
\title{
BReserch S Suare \\ The effect of the lead error on the load distribution and no-load drag torque in a double-nut ball screw
}

\author{
Lu-Chao Zhang \\ Nanjing University of Science and Technology \\ Yi Ou ( $\nabla$ ouyi3281289@163.com ) \\ Nanjing University of Science and Technology \\ Hu-Tian Feng \\ Nanjing University of Science and Technology
}

\section{Original Article}

Keywords: ball screw, lead error, drag torque, preload, load distribution

Posted Date: February 19th, 2021

DOl: https://doi.org/10.21203/rs.3.rs-206937/v1

License: (1) This work is licensed under a Creative Commons Attribution 4.0 International License.

Read Full License 


\title{
The effect of the lead error on the load distribution and no-load drag torque in a double-nut ball screw
}

\author{
Lu-Chao Zhang, Yi Ou*, Hu-Tian Feng \\ Department of Mechanical Engineering. Nanjing University of Science and Technology, \\ Nanjing 210094, China \\ *Corresponding author. Tel: +86 19851890050; fax: +86 2584315619 \\ E-mail address: ouyi3281289@163.com.
}

\begin{abstract}
In a ball screw mechanism, the lead error is not only the key parameter to evaluate the precision, but also an important parameter to determine the load distribution. In this paper, a model is proposed to predict the load distribution related to the lead errors. The mechanical analysis of a double-nut ball screw is conducted to investigate the effect of the lead errors on the balls' contact deformations and contact angles. Based on the Hertz contact theory, the equations to predict the preload and no-load drag torque are established, and the amplitude of the preload is obtained when the rotational speed is low. To verify the model, various experiments are conducted to measure the lead errors and the no-load drag torques of the ball screw by changing the screws with different accuracy levels. The experimental results show that the preload and no-load drag torque rise when the lead error increases in a double-nut ball screw. Besides, the relative errors between the experimental value and the theoretical value are less than $10 \%$. This proves that the model can predict the preload and the no-load drag torque influenced by the lead error well, which is beneficial to the design of the double-nut ball screw for a certain preload.
\end{abstract}

Keywords: ball screw; lead error; drag torque; preload; load distribution

\section{Introduction}

A double-nut ball screw is a mechanism of high positioning accuracy and is wildly applied in the CNC machine tools [1]. However, there is always a lead error in the ball screw due to the errors in machining, which decreases the positioning accuracy of the ball screw. Meanwhile, the load distribution of the ball screw is influenced by the lead error. This will change the required preload and the no-load drag torque of the ball screw.

In recent years, the research on the load distribution of ball screw takes the axial load, the turning torque, the contact stiffness, the radial displacement, the geometry errors, the nut's deformation, and the screw's deformation into account. Mei et al.[2] established a model to analyze the load distribution of the ball screw, considering the axial load, the geometry errors, the nut' deformation, and the screw' deformation. The results showed that the nut and screw's deformation affected the balls' contact loads differently under various load conditions. Considering the radial force, Zhen et al. [3] proposed a calculation model to investigate the contact force and fatigue life of the ball screw based on the mechanics analysis. The load distribution fluctuated because of the radical force. Based on Zhen's method, Zhao et al. [4] investigated the load distribution of the ball screw considering the turning torque and geometric error. The results showed 
that the amplitude of the balls' contact load kept changing from the first circle to the last one. Du et al. [5] studied the dynamic character of the ball screw, and the results showed that the contact deformation is nonlinear, which meant the contact loads of the balls were different. In order to analyze the load distribution of the ball screw, the experiments were conducted to investigate the static and dynamic character of the ball screw, and the experimental results showed that the load distribution of the ball screw kept changing [6][7].

When the load distribution of the ball screw changes, the preload and no-load drag torque will change. In Zhou's study [8], a new arm of friction force was proposed, and the calculation of the no-load drag torque was constructed based on the new arm of friction force. The calculation results agreed well with the experimental results. However, it was assumed that the load distribution was uniform and the contact angle of the balls was the same in Zhou' model, which is not exact. Based on the systematic creep analysis, $\mathrm{Xu}$ et al. [9] calculated the friction force and analyzed the effect of the creep parameters on the friction torque of the ball screw. Nevertheless, the experiment was conducted only under 100rpm, which limited its application. Applying the method of Angular Velocity Vold-Kalman Filtering Order Tracking, Tsai et al. [10] investigated the preload loss by detecting the ball' passing frequency and found that the ball' passing frequency increased when the preload decreased. The relationship between the balls' contact load and the preload was ignored. The contact loads of the balls were considered the same in the mentioned research about the friction torque of the ball screw, which is not accurate for the load distribution.

The mentioned research above has paid much attention to the deformation and mechanics of the ball screw, while the effect of the dimensions especially the lead error on the load distribution and the contact angle of the ball screw are ignored. The effect of the lead error on the no-load drag torque of the ball screw, a basic performance, needs to be investigate as well.

In order to calculate the no-load drag torque of a double-nut ball screw, the contact load of every ball needs to be obtained, and the influence of the lead error on the load distribution must be taken into consideration. Thus, in this paper, a more exact model to calculate the load distribution and the no-load drag torque is established considering the effect of the lead error. The variation of the preload is predicted at the same time. This is beneficial to estimate the performance and vibration characteristics when the ball screw is in operation.

\section{Theoretical analysis}

\subsection{The load distribution considering lead error}

In terms of the double-nut ball screw shown in Fig. 1, a preload exists between the two nuts due to the spacer. When the dimensions of the nut, the screw, and the spacer are determined, the value of the preload is definite. However, there is always a lead error on the screw during the machining process, which will lead to a fluctuation in the realistic preload. 


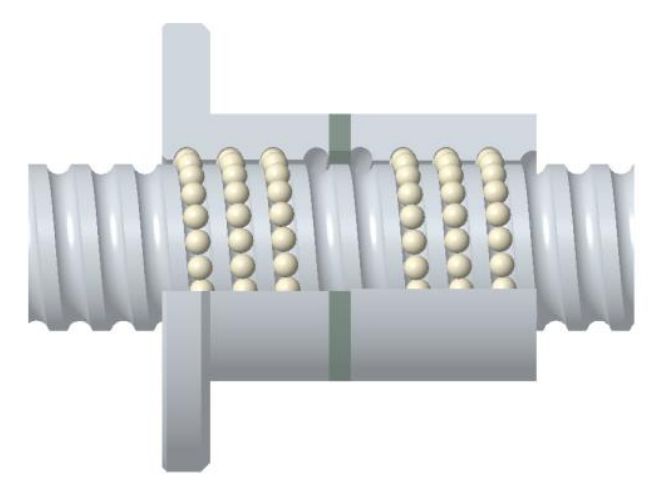

Fig. 1 The structure of a double-nut ball screw

The difference between the actual travel and specified travel (short as $E_{T}$ ) of a double-nut ball screw of the ball screw is shown in Fig. 2. There is an approximate linear correlation between $E_{T}$ and the specified travel. Thus, it is assumed that the lead error is the slope of the fitted line in Fig. 2. Most of the time, the lead error is negative in order to overcome an expected elongation caused by the temperature rising or the load [11]. Thus, the value of lead error is considered as a negative number in this paper.

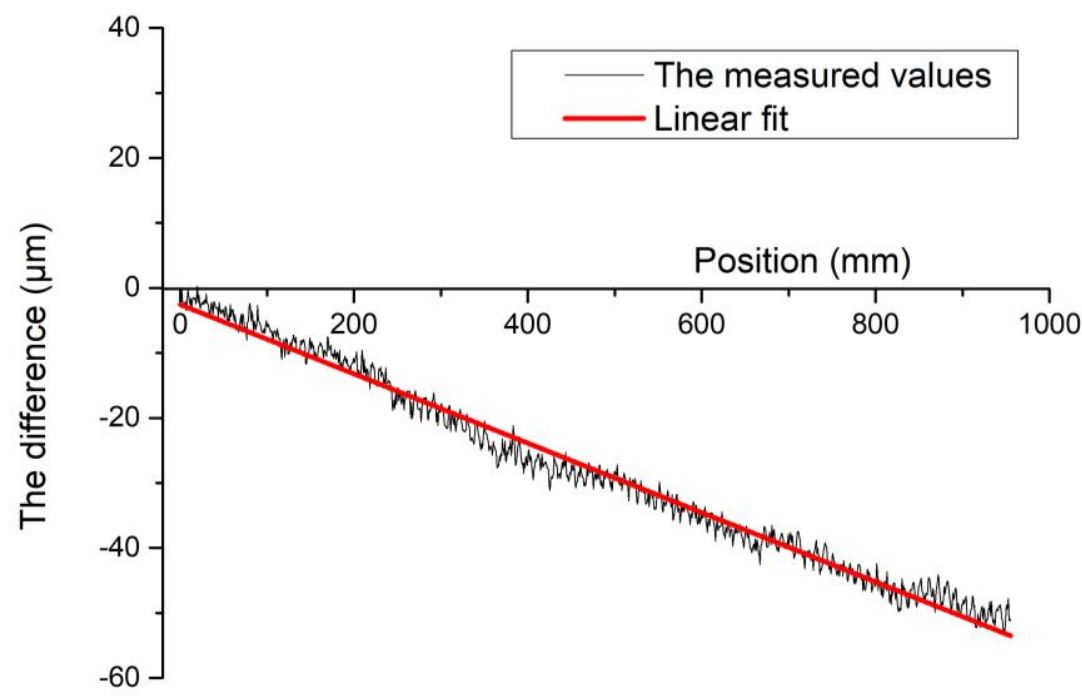

Fig. 2 The difference between the actual travel and specified travel of a double-nut ball screw

As shown in Fig. 3, when a lead error $\delta$ exists on the screw, the screw raceway's center will occur a certain displacement in the axial direction. The mechanics analysis of the double-nut ball screw shows that the plane in the middle of the screw is a fixed plane when the ball screw withstands no axial load except for the preload. Thus, the lead error $\delta$ is calculated from the fixed plane to the both sides. In this paper, there is a $20 \mathrm{~mm}$ gap between nut $\mathrm{A}$ and nut $\mathrm{B}$. So the $L_{s}=1.5 P_{h}$, and the axial displacement of the $i$ th ball can be described as Eq. (1).

$$
\Delta L_{i}=\frac{(i-1) \mathrm{g} \delta}{n}+1.5 \mathrm{~g} \delta
$$

In terms of the double-nut ball screw, it is not able to measure the friction torque of a single nut, and there is little difference between the friction torque of the two nuts. Thus, it is considered that the friction forces of the two balls are the same. 


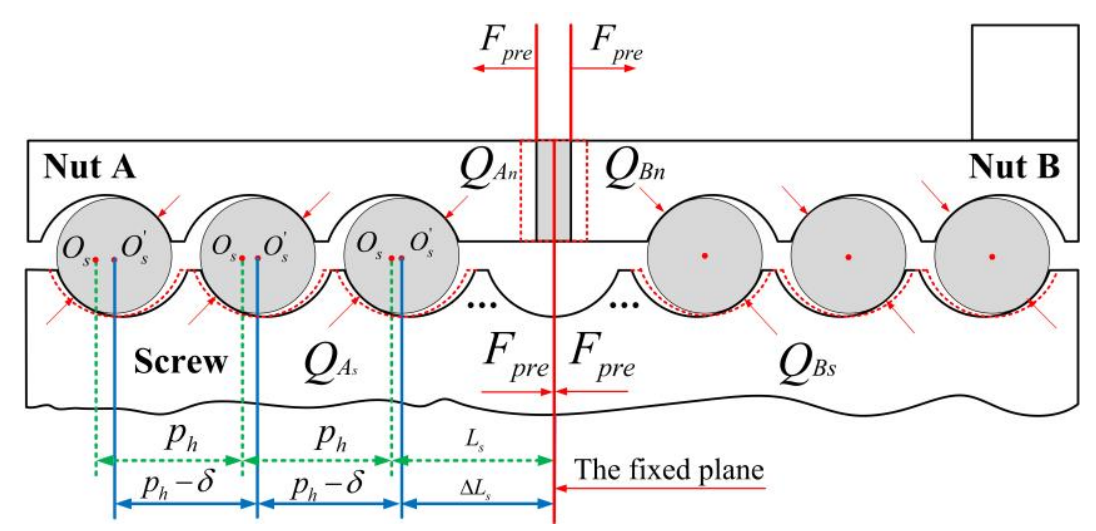

Fig. 3 The displacement analysis of the screw under a preload

In terms of the $i$ th ball, the deformation and displacement are shown in Fig. $4 . \Delta L_{i}^{\prime}$ is the projection of the $i$ th ball's axial displacement in the normal section. Thus, the contact angle $\alpha_{i}$ and the displacement $\Delta L_{i}^{\prime}$ can be described as [3]

$$
\begin{gathered}
\sin \alpha_{i}=\frac{E \operatorname{gsin} \alpha_{0}+\Delta L_{i}^{\prime}+L}{O_{n} O_{s}^{\prime}} \\
\Delta L_{i}^{\prime}=\frac{\Delta L_{i}}{\cos \beta} \\
E=r_{n}+r_{s}-d_{b} \\
O_{n} O_{s}^{\prime}=\sqrt{\left(E \operatorname{gcos} \alpha_{0}\right)^{2}+\left(E \operatorname{gsin} \alpha_{0}+\Delta L_{i}^{\prime}+L\right)^{2}}
\end{gathered}
$$

Thus, the contact deformation and contact force of the $i$ th ball can be expressed as

$$
\begin{gathered}
\delta_{i}=O_{n} O_{s}^{\prime}-E=\sqrt{\left(E g \cos \alpha_{0}\right)^{2}+\left(E \operatorname{gsin} \alpha_{0}+\Delta L_{i}^{\prime}+L\right)^{2}}-E \\
Q_{i}=K g \delta_{i}^{\frac{3}{2}} \\
F_{i}=K g \delta_{i}^{\frac{3}{2}} \operatorname{gsin} \alpha_{i} \operatorname{gcos} \beta
\end{gathered}
$$

The total preload of a double-nut ball screw with the lead errors can be described as

$$
F_{\text {pre }}=\sum_{i=1}^{63} K g \delta_{i}^{\frac{3}{2}} \operatorname{gsin} \alpha_{i} \operatorname{gcos} \beta
$$

According to Zhou's model [8], the correlation between the preload and the friction torque of the $i$ th ball and the total friction torque of nut A can be described as

$$
\begin{gathered}
M_{i}=\frac{\mu \mathrm{g} Q_{i} \mathrm{~g}\left(r_{m}+r_{b} \mathrm{~g} \cos \alpha_{i}\right)}{\sin \alpha_{i}} \\
M_{\text {pre }}=\sum_{i=1}^{63} \mu \mathrm{g} K g \delta_{i}^{\frac{3}{2}} \mathrm{~g} \cos \beta\left(r_{m}+r_{b} \mathrm{~g} \cos \alpha_{i}\right)
\end{gathered}
$$

The load distribution and deformation of the two nuts are the same, so the no-load drag friction torque of the double-nut ball screw can be described as 


$$
M_{B S}=2 \mathrm{~g} M_{p r e}=2 \sum_{i=1}^{63} \mu \mathrm{g} K \mathrm{~g} \delta_{i}^{\frac{3}{2}} \operatorname{gcos} \beta \mathrm{g}\left(r_{m}+r_{b} \operatorname{gcos} \alpha_{i}\right)
$$

$L$ is a parameter determined by the interference of the spacer to provide an initial preload. $L$ can be calculated when the preload is given. In this paper, $L$ is obtained by the detected friction torque. Thus, the no-load drag friction torque of the double-nut ball screw can be captured when the lead error $\delta$ is detected.

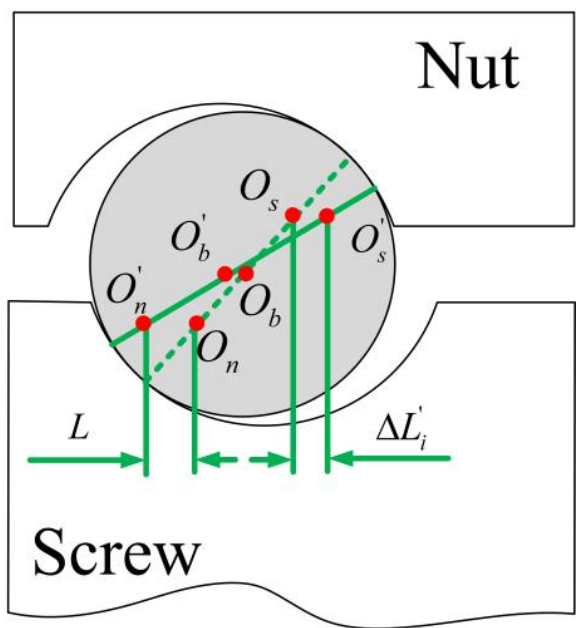

Fig. 4 The deformation and displacement of the $i$ th ball

\subsection{An exact analysis on the preload fluctuation}

For the ball screw mechanism, there is a certain distance between the adjacent balls. When the ball screw is operated at a low speed, the position of every ball will change, as shown in Fig. 5. $\theta_{\text {ave }}$ is the angle between the adjacent balls. When the first ball rotates by a specific turning angle $\theta$, and $\theta$ is smaller than $\theta_{\text {ave }}$, the position of every ball will be changed, which will affect the load distribution of the balls because of Ep. When $\theta$ is equal to $\theta_{\text {ave }}$, the whole ball chain will be the same as that when $\theta$ is zero. Thus, a cycle exists in the operation of the balls' movement.
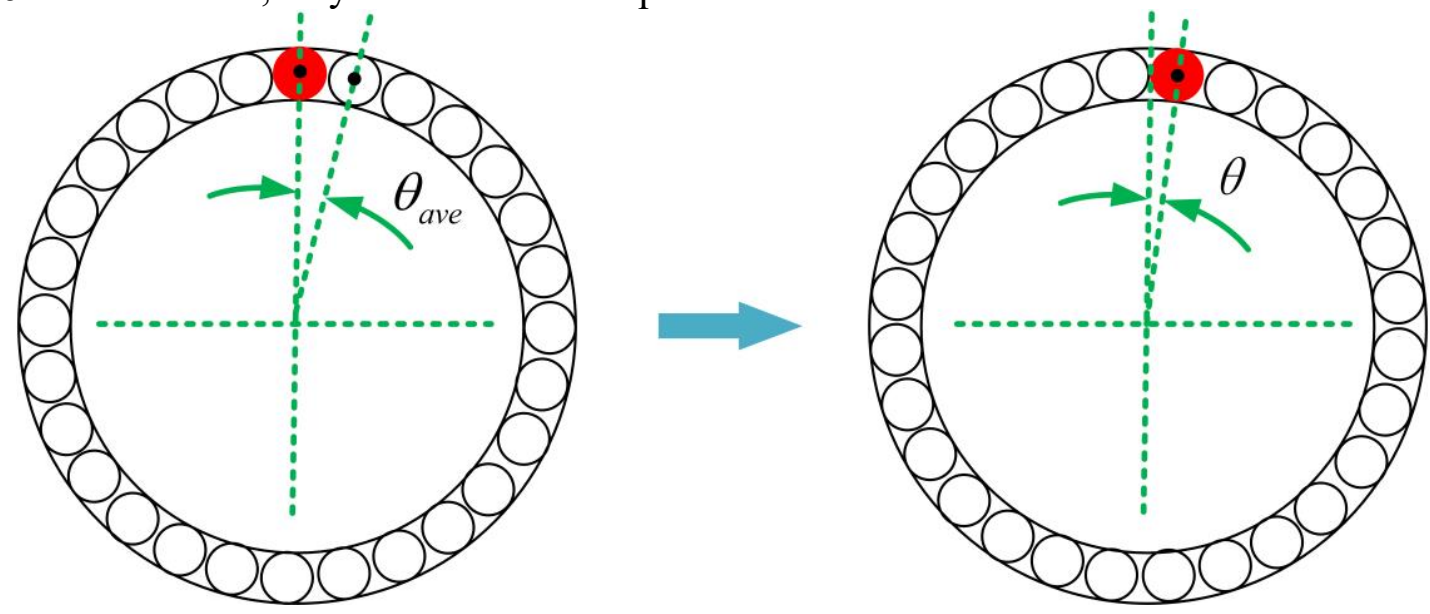

Fig. 5 the movement of the balls in the raceway

When $\theta$ is from zero to $\theta_{\text {ave }}$, the axial displacement of the $i$ th ball can be described as Eq. (13). 


$$
\Delta L_{i}^{\theta}=\frac{(i-1) \mathrm{g} \delta}{n}+\frac{\theta \mathrm{g} \delta}{2 \mathrm{~g} \tau}+1.5 \mathrm{~g} \delta
$$

Thus, the preload can be obtained by Eq. (9), and the preload fluctuation can be obtained when $\theta$ is from zero to $\theta_{\text {ave }}$.

$$
F_{p r e}^{\theta}=\sum K g \delta_{i}^{\frac{3}{2}} \operatorname{gsin} \alpha_{i} \operatorname{gcos} \beta
$$

\section{The experiment verification}

In order to verify the model, the lead errors and the no-load drag torque are measured in this paper. The lead errors are measured by the ball screw lead errors measuring instrument shown in Fig. 6. The measuring instrument consists of a servo motor, a worktable, a gas floating platform, a laser interferometer, and a circular grating. The servo motor provides a rotational speed for the screw. The worktable is supported by the precise gas floating platform support to travel along the axial direction smoothly. The axial position of the screw is measured by the laser interferometer, while the rotation angle of the screw is measured by the circular grating. When the axial position and the rotation angle is obtained, the lead error of the screw can be calculated.

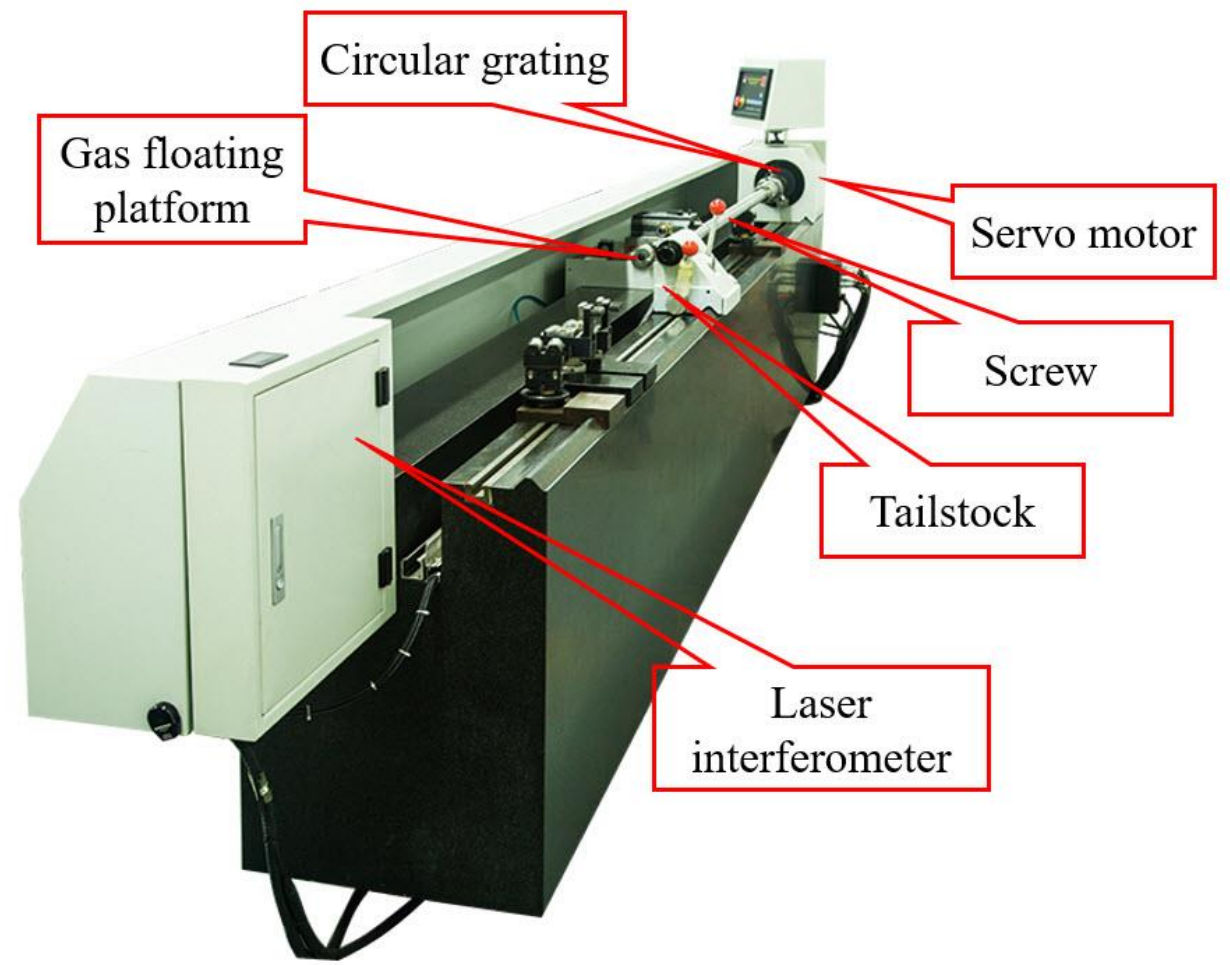

Fig. 6 The structure of the ball screw lead errors measuring instrument

The friction torque of the ball screw is measured by the ball screw friction torque measuring instrument shown in Fig. 7. The measuring instrument consists of a servo motor, a worktable, a pair of rolling linear guides, and a force sensor. The servo motor provides a rotational speed for the ball screw. The worktable is supported by the rolling linear guides to travel along the axial direction. The force sensor is connected to the worktable and can capture the friction force of the ball screw. Afterward, the friction torque of the ball screw is computed by the software. 


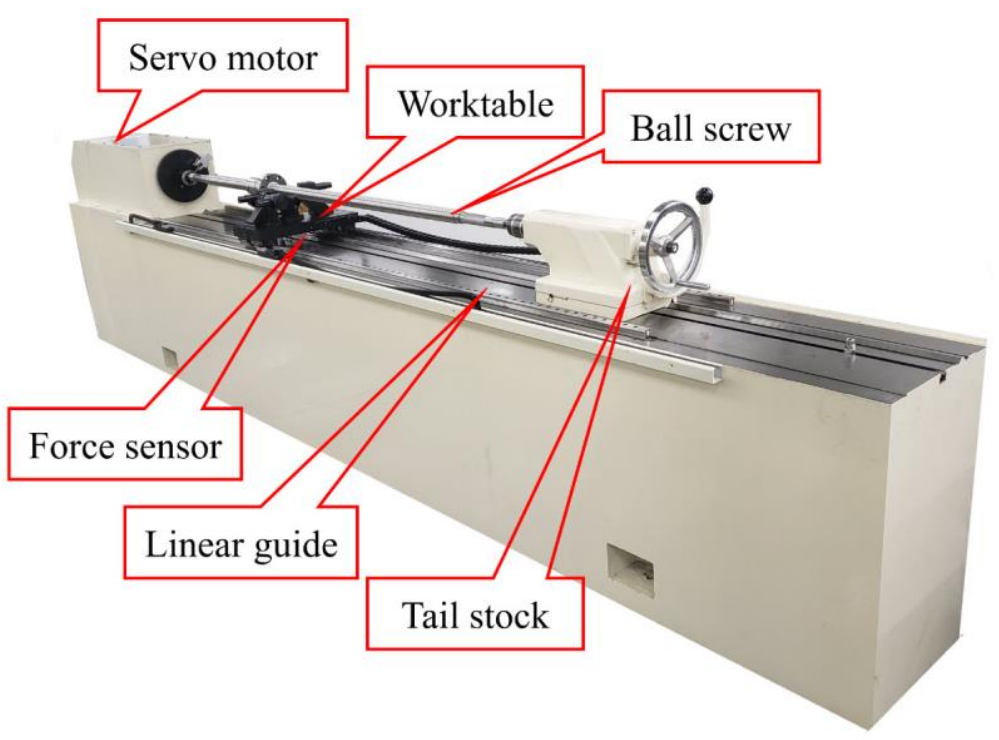

Fig. 7 The structure of the ball screw no-load drag torque measuring instrument

In this experiment, many ball screws of the same type are measured. The parameters of the ball screws are shown in Tab. 1. A series of screws of different precision levels are measured without nut to obtain the lead errors. Then, every screw is fitted with the same spacer, the balls, and the nuts with a lead error $-0.041 \mu \mathrm{m}$. The friction torque of the ball screw is measured and saved according to the ISO standards [12]. When the no-load drag torque of the ball screw is measured, the screw will be replaced by another screw, while the nut, balls, and the spacer are not replaced.

Tab. 1 The parameters of the tested ball screws

\begin{tabular}{lcc}
\hline Parameters & Value & Unit \\
\hline Radius of the ball $r_{b}$ & 2.9765 & $\mathrm{~mm}$ \\
Nominal radius of ball screw $r_{m}$ & 20 & $\mathrm{~mm}$ \\
Radius of the nut raceway $r_{n}$ & 3.304 & $\mathrm{~mm}$ \\
Radius of the nut raceway $r_{s}$ & 3.304 & $\mathrm{~mm}$ \\
Thickness of the spacer & 8 & $\mathrm{~mm}$ \\
Helix angle $\beta$ & 4.55 & degree \\
Contact angle $\alpha_{0}$ & 45 & degree \\
Nominal lead $P_{h}$ & 10 & $\mathrm{~mm}$ \\
Environment temperature & 20 & Celsius \\
Ball' number & 63 & \\
Friction coefficient $\mu$ & 0.0045 & \\
\hline
\end{tabular}

\section{Results and discussion}

The contact load distribution of the balls under different lead errors is calculated by Eq. (8), as shown in Fig. 8. When the lead error is zero, the contact load distribution of the balls is relatively uniform. When the lead error increases, the contact load of increases from the first ball to the last one. It demonstrates that the lead error influences the load distribution of the ball screw obviously, and the further the ball is from the spacer, the bigger the contact load is. The reason is that the lead error is close to the balls' contact deformation and increases with the distance to the spacer. The deformations of the nut and screw are much smaller than the contact deformations [2]. 
The bigger the lead error is, the higher the increasing rate of the contact load is. So, it is the same as the contact angle of the balls. According to Fig. 9, the contact angle of the balls rises when the lead error increases. When the ball is far away from the spacer, the contact angle becomes bigger. There is a linear relationship between the contact angle and the distance to the spacer. According to Eq. (1), the gap between the two nuts increases the axial displacement of the screw raceway's center, which will lead to an increase in the contact load. Thus, it is necessary to make the gap between the two nuts smaller.

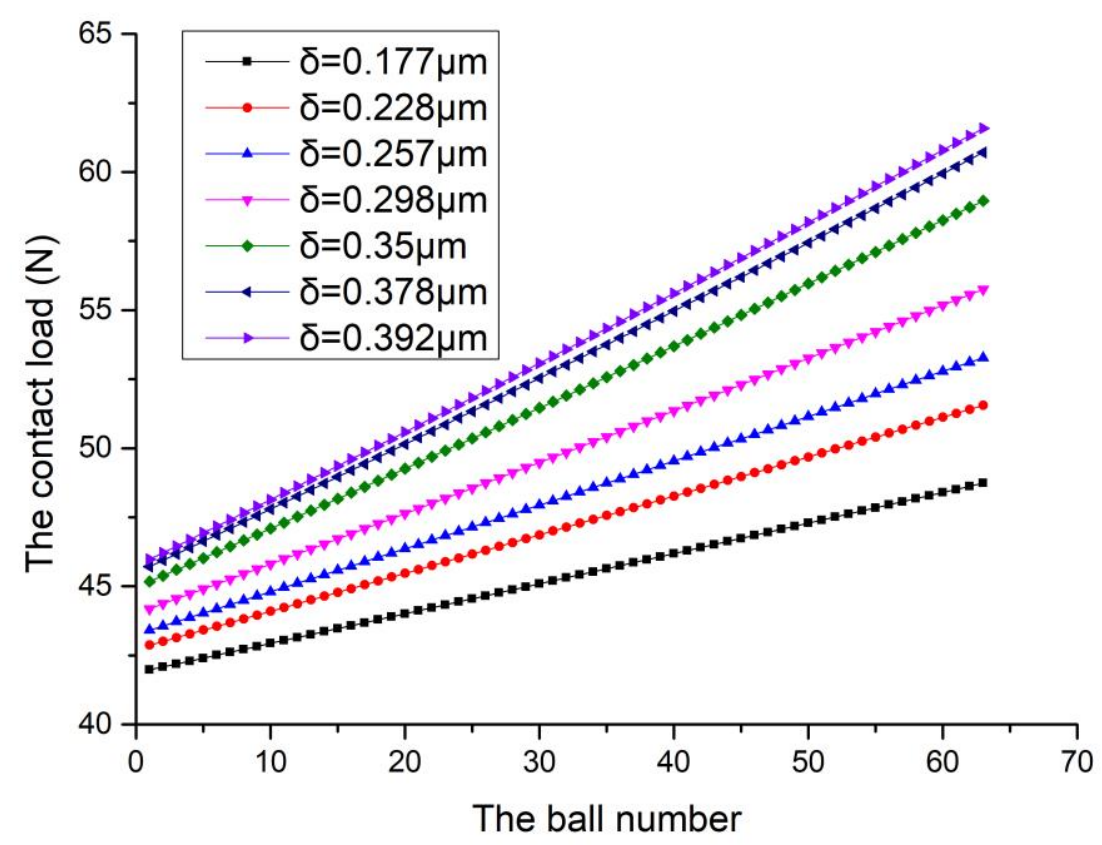

Fig. 8 The contact load of the balls under different lead errors

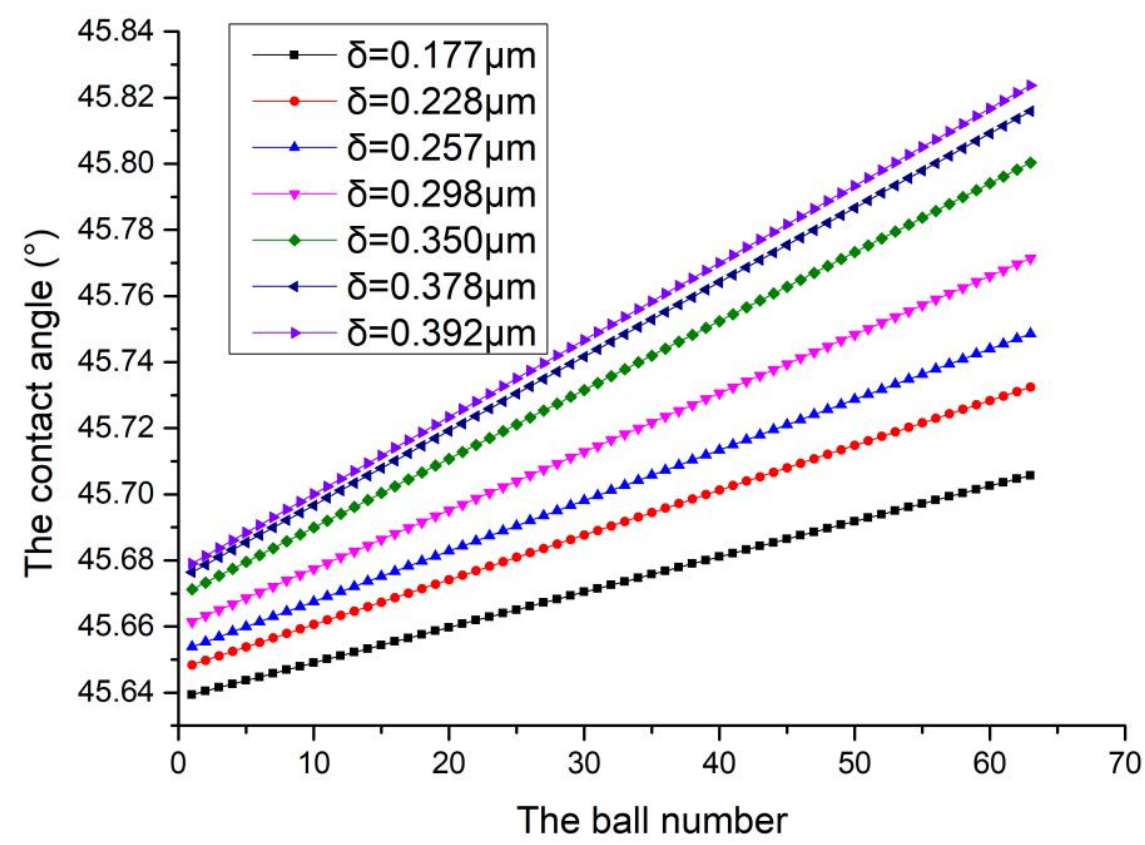

Fig. 9 The contact angle of the balls under different lead errors 
According to Fig. 10, the balls' contact loads increase when the lead errors increase, and the increasing rate of the balls' contact loads are Approximately proportional to the lead error.

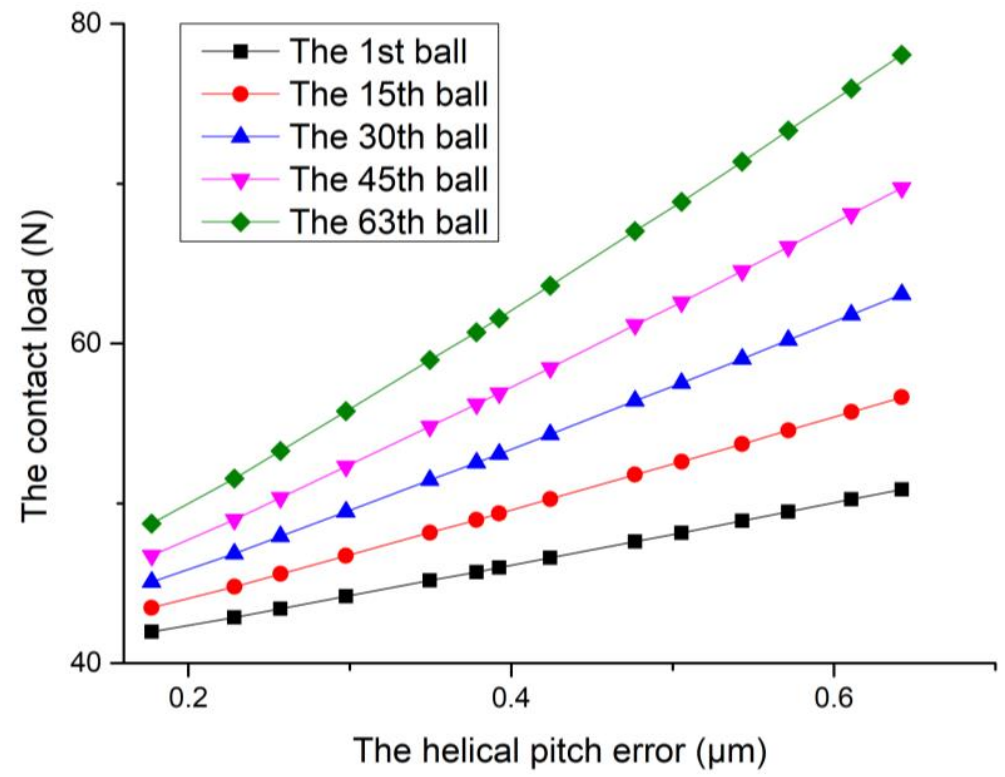

Fig. 10 The relationship between the ball's contact load and the lead error

The axial displacement $L$ is calculated in Fig. 11 by the proposed model when the friction torque is measured. In this paper, the initial value of $L$ is determined when the lead error is $0.177 \mu \mathrm{m}$ because the smaller lead error is, the closer the value of $L$ is to the theoretical value. The value of $L$ decreases when the lead error increases. This is because the deformation of the ball screw increases when the applied force on the ball screw increases.

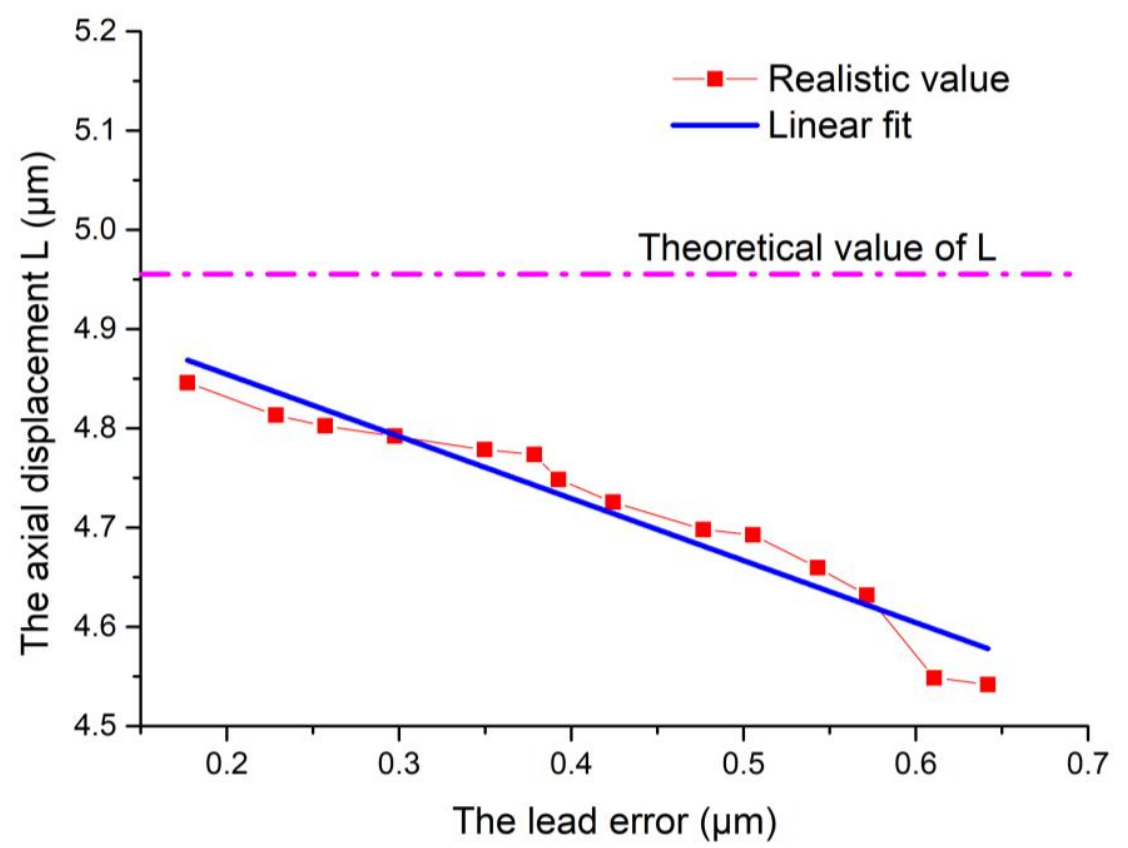

Fig. 11 The calculated $L$ under different lead errors

The experimental results and the theoretical results of the no-load drag torque 
based on the proposed model are shown in Tab. 2. The theoretical values of the preload are calculated as well.

Tab. 2 The experimental results and the theoretical results of the preload and no-load drag torque

\begin{tabular}{ccccccc}
\hline \multirow{2}{*}{ screw } & $\delta$ & $F_{\text {pre }}^{\prime}$ & $F_{\text {pre }}$ & $M_{\text {test }}$ & $M_{B S}$ & \multirow{2}{*}{$\begin{array}{c}\text { Relative } \\
\text { error of } M\end{array}$} \\
\cline { 2 - 5 } & $\mu \mathrm{m}$ & $\mathrm{N}$ & $\mathrm{N}$ & $\mathrm{Nm}$ & $\mathrm{Nm}$ & $2.91 \%$ \\
1 & 0.177 & 1966 & 2038 & 0.55 & 0.566 & $2.53 \%$ \\
2 & 0.228 & 2033 & 2126 & 0.57 & 0.589 & $3.33 \%$ \\
3 & 0.257 & 2076 & 2177 & 0.58 & 0.603 & $3.97 \%$ \\
4 & 0.298 & 2140 & 2250 & 0.60 & 0.623 & $3.83 \%$ \\
5 & 0.350 & 2222 & 2344 & 0.62 & 0.648 & $4.52 \%$ \\
6 & 0.378 & 2268 & 2395 & 0.63 & 0.662 & $5.08 \%$ \\
7 & 0.392 & 2278 & 2421 & 0.64 & 0.669 & $4.53 \%$ \\
8 & 0.424 & 2321 & 2480 & 0.65 & 0.686 & $5.54 \%$ \\
9 & 0.477 & 2399 & 2580 & 0.67 & 0.713 & $6.42 \%$ \\
10 & 0.505 & 2446 & 2633 & 0.68 & 0.727 & $6.91 \%$ \\
11 & 0.543 & 2495 & 2706 & 0.70 & 0.747 & $6.71 \%$ \\
12 & 0.572 & 2531 & 2762 & 0.71 & 0.763 & $7.46 \%$ \\
13 & 0.611 & 2552 & 2838 & 0.72 & 0.783 & $8.75 \%$ \\
14 & 0.642 & 2605 & 2899 & 0.73 & 0.800 & $9.59 \%$ \\
\hline
\end{tabular}

As Fig. 12 and Fig. 13 show, the experimental friction torque is smaller than the theoretical friction torque due to the effect of the deformations of the ball screw. There is an appropriate linear correction between the friction torque and the lead error. When the lead error increases, the difference between the experimental and the theoretical results. In terms of the preload, the theoretical and experimental values rise when the lead error increases. Meanwhile, the difference between theoretical and experimental values increases when the lead error gets higher.

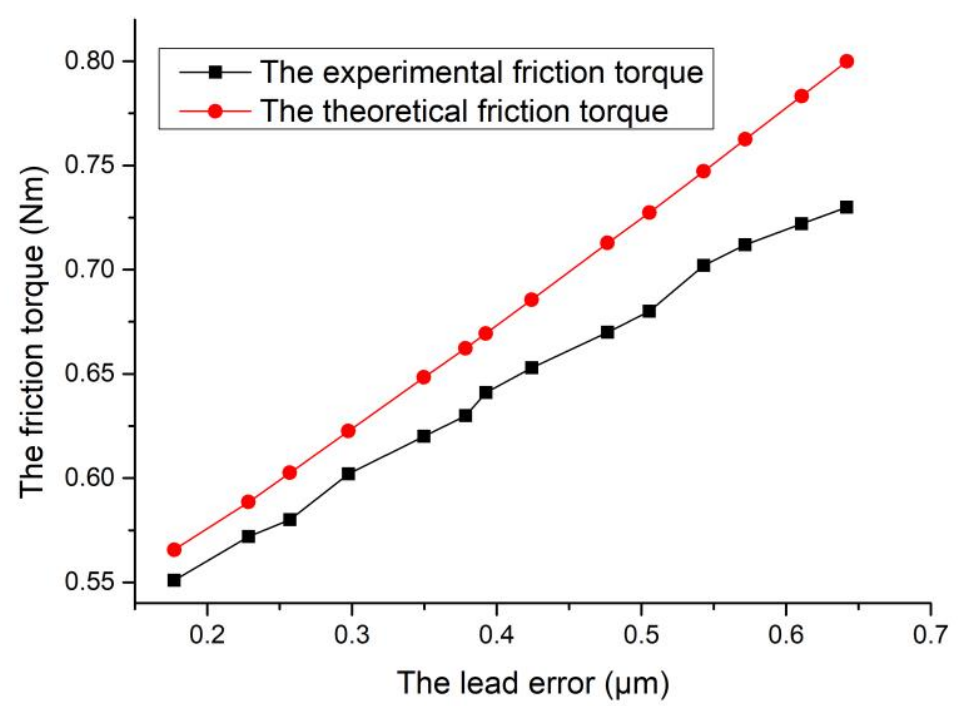

Fig. 12 The relationship between the friction torque and the lead error 


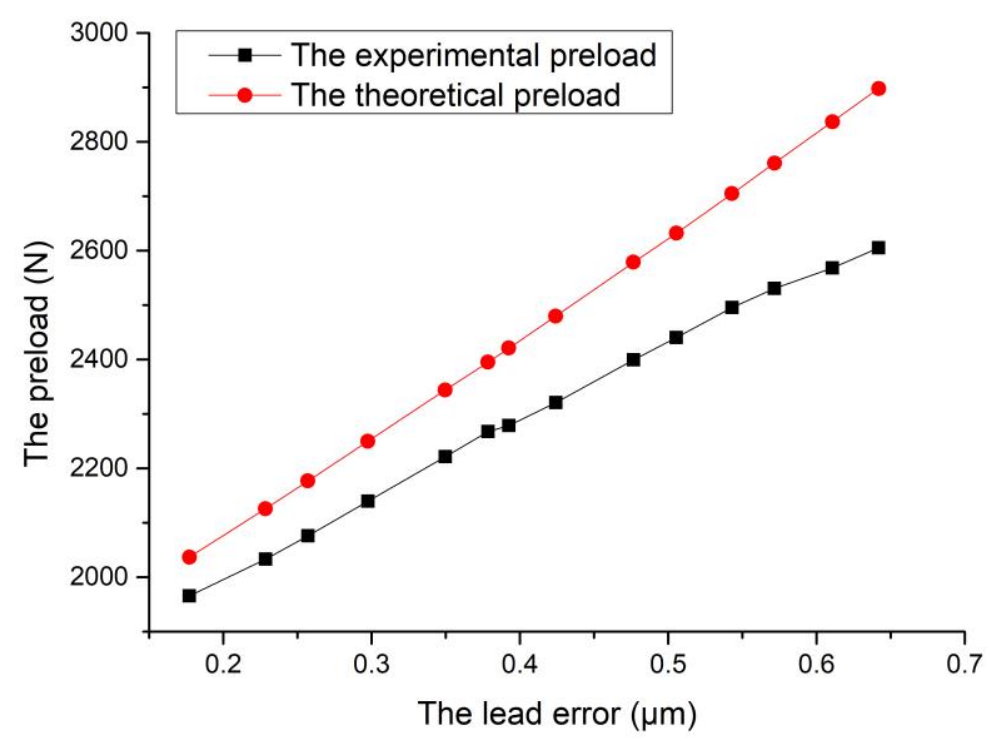

Fig. 13 The relationship between the preload and the lead error

As Fig. 14 shows, the preload of a double-nut ball screw keeps changing when the turning angle $\theta$ rise. When $\theta$ is smaller than the $\theta_{\text {ave }}$, the preload keep increasing. This is because the displacement of the screw increases with the turning angle. When $\theta$ is equal to $\theta_{\text {ave }}$, the preload declines suddenly as the first ball reaches the position of the second ball, and the last ball reaches the position of the first ball. Thus, the load condition will be the same as $\theta=0$. When the turning angle keeps increasing, the magnitude of the preload starts to circulate.

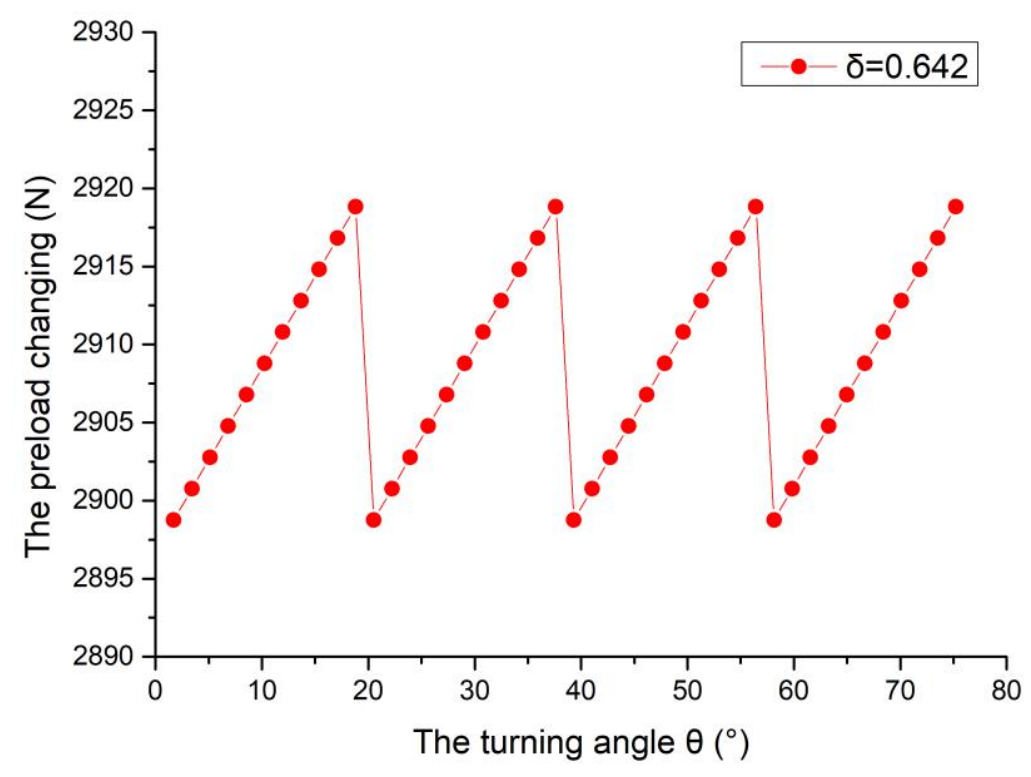

Fig. 14 The correlation between the preload and the turning angle $\theta$

According to Fig. 15 and Fig. 16, the preload increasing rate is positive to the lead error. The larger the lead error is, the bigger the increasing rate of the preload is. This is because the lead error increases the deformation of the contact ball. The amplitude of the preload with the lead error. The changing range of the preload is smaller than 
$21 \mathrm{~N}$ when the lead error is within $0.642 \mu \mathrm{m}$. There is an appropriate linear relationship between the vibration of the preload and the lead errors.

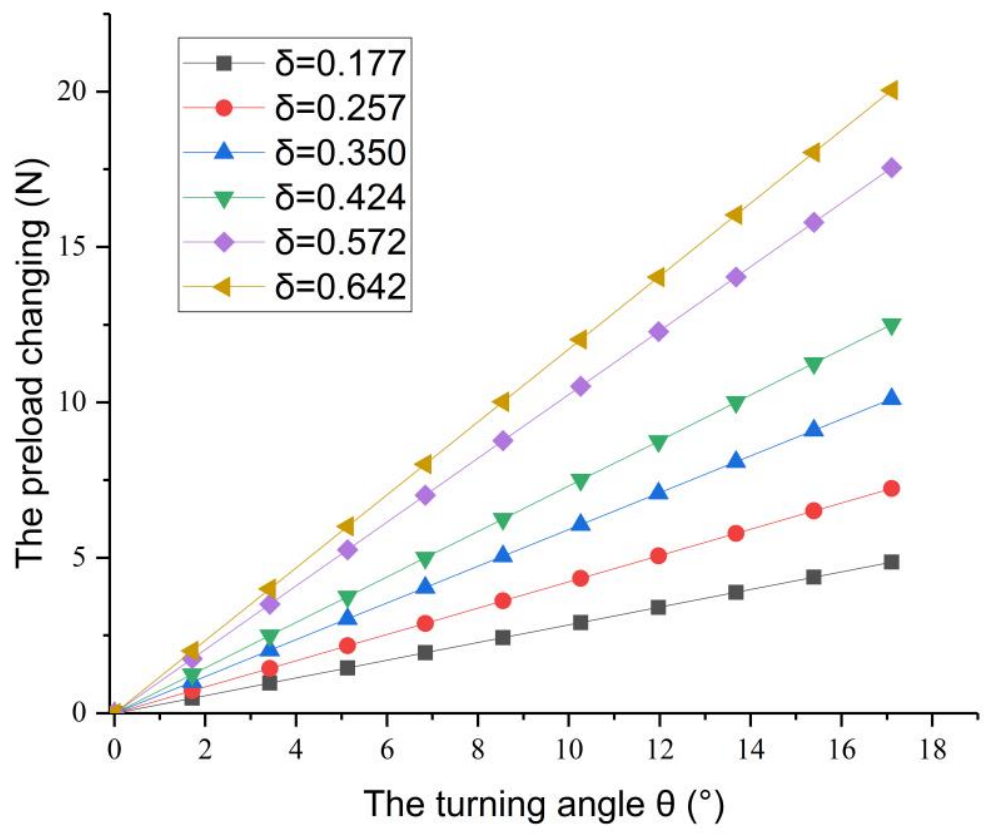

Fig. 15 The relationship between the preload and the turning angle

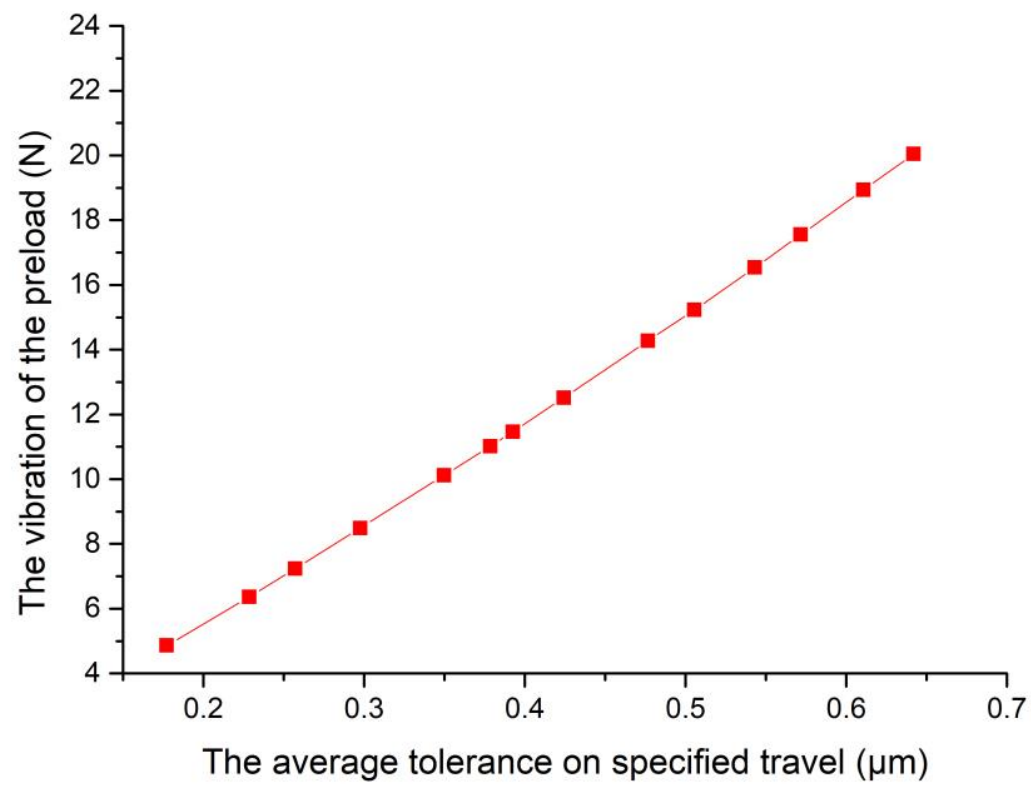

Fig. 16 The vibration of the preload under different lead errors

\section{Conclusion}

In this paper, a new model is proposed to predict the load distribution of the ball screw, considering the lead errors of the screw. The preload and no-load drag torque of the ball screw are calculated by this model, and the calculation results show that the preload and no-load drag torque change with the lead error. The contact load of the balls 
is related to the balls' position to the fixed plane. Meanwhile, the value of the preload fluctuates when the ball screw rotates at a low speed. In order to prove the accuracy of the model, the lead error and the no-load drag torque are measured in this paper. The main results are listed as follows

(1) For a double-nut ball screw without the axial load, the balls' contact load and contact angle increase with the lead error. Besides, the contact load and contact angle and increase when the ball is away from the spacer, when the lead error is a negative number.

(2) The preload of a double-nut ball screw keeps fluctuating when the ball screw rotates. The changing amplitude of the preload increases with the lead error rising. The changing range of the preload is within $21 \mathrm{~N}$ when the lead error is within $0.642 \mu \mathrm{m}$ in this paper.

(3) The distance between the two nuts influences the load distribution of the doublenut ball screw. The smaller the distance between the two nuts is, the smaller the total contact load will be when the geometry of the nut raceway is not changed.

(4) There is an appropriate linear relationship between the no-load drag torque and the lead errors, and relative error between the experimental values and the theoretical values calculated by this model is within $10 \%$.

\section{Declaration of interests}

The authors declare that they have no known competing financial interests or personal relationships that could have appeared to influence the work reported in this paper.

\section{Data Availability}

All data, models, and code generated or used during the study appear in the submitted article.

\section{Acknowledgment}

The authors appreciate the Key Laboratory of Performance Test and Reliability Technology for CNC Machine Tool Components of China Machinery Industry for providing the test benches and experiment materials. At the same time, the authors greatly appreciate the National Natural Science Foundation of China (Grant No. 51905274), and National Science and Technology Major Projects of China (Grant No. 2018ZX04039001) for support.

\section{Authors' contributions}

Luchao Zhang prepared the manuscript, Yi Ou conducted Data processing, and Hutian Feng check the manuscript.

\section{Nomenclature}

$F_{i} \quad$ The axial projection of the $i$ th $\quad M_{i} \quad$ The friction torque of the $i$ th ball's contact load ball 


\begin{tabular}{|c|c|c|c|}
\hline$M_{\text {test }}$ & $\begin{array}{l}\text { The measured no-load drag } \\
\text { torque }\end{array}$ & $M_{\text {pre }}$ & $\begin{array}{l}\text { The friction torque caused by } \\
\text { the preload on every nut }\end{array}$ \\
\hline$M_{B S}$ & $\begin{array}{l}\text { The calculated friction torque } \\
\text { based on this model }\end{array}$ & $\Delta L_{i}^{\prime}$ & $\begin{array}{l}\text { The axial projection of } \Delta L_{i} \\
\text { under the turning angle } \theta\end{array}$ \\
\hline$F_{\text {pre }}$ & The preload of the ball screw & $O_{n}$ & The center of the nut raceway \\
\hline$K$ & $\begin{array}{l}\text { The stiffness coefficient of the } \\
\text { ball screw }\end{array}$ & $\mu$ & $\begin{array}{l}\text { The friction coefficient of the } \\
\text { ball screw }\end{array}$ \\
\hline$O_{s}$ & $\begin{array}{l}\text { The center of the screw } \\
\text { raceway before deformation }\end{array}$ & $O_{s}^{\prime}$ & $\begin{array}{l}\text { The center of the nut raceway } \\
\text { after deformation }\end{array}$ \\
\hline$O_{b}$ & $\begin{array}{l}\text { The center of the ball before } \\
\text { deformation }\end{array}$ & $O_{b}^{\prime}$ & $\begin{array}{l}\text { The center of the ball after } \\
\text { deformation }\end{array}$ \\
\hline$r_{s}$ & $\begin{array}{l}\text { The radius of the screw } \\
\text { raceway }\end{array}$ & $r_{n}$ & The radius of the nut raceway \\
\hline$d_{b}$ & The diameter of the balls & $r_{b}$ & The radius of the balls \\
\hline$E$ & $\begin{array}{l}\text { The distance between the } \\
\text { centers of the screw and nut } \\
\text { raceway }\end{array}$ & $E_{T}$ & $\begin{array}{l}\text { The difference between the } \\
\text { specified travel and the actual } \\
\text { travel }\end{array}$ \\
\hline$L_{S}$ & $\begin{array}{l}\text { The axial displacement of the } \\
\text { nuts caused by the spacer }\end{array}$ & $L$ & $\begin{array}{l}\text { The axial displacement of the } \\
\text { nuts caused by the spacer }\end{array}$ \\
\hline$\alpha_{0}$ & The initial contact angle & $\beta$ & $\begin{array}{l}\text { The helix angle of the ball } \\
\text { screw }\end{array}$ \\
\hline$\Delta L_{i}$ & $\begin{array}{l}\text { The axial displacement of the } \\
i \text { th ball }\end{array}$ & $\Delta L_{i}^{\prime}$ & The axial projection of $\Delta L_{i}$ \\
\hline$\theta$ & The turning angle of the balls & $Q_{i}$ & The contact load of the $i$ th ball \\
\hline$F_{\text {pre }}^{\theta}$ & $\begin{array}{l}\text { The calculated preload under } \\
\text { the turning angle } \theta\end{array}$ & $F_{\text {pre }}^{\prime}$ & $\begin{array}{l}\text { The calculated preload based } \\
\text { on } M_{\text {test }}\end{array}$ \\
\hline$n$ & $\begin{array}{l}\text { The total number of the balls } \\
\text { in a circle }\end{array}$ & $r_{m}$ & $\begin{array}{l}\text { The nominal radius of ball } \\
\text { screw }\end{array}$ \\
\hline$\theta_{\text {ave }}$ & $\begin{array}{l}\text { The angle between the } \\
\text { adjacent balls }\end{array}$ & $p_{h}$ & The lead of the ball screw \\
\hline$\delta$ & The lead error of the screw & $O_{b}^{\prime}$ & $\begin{array}{l}\text { The center of the nut raceway } \\
\text { after deformation }\end{array}$ \\
\hline$O_{n} O_{s}$ & $\begin{array}{l}\text { The distance between the } \\
\text { center of the nut and screw } \\
\text { raceway }\end{array}$ & $O_{n} O_{s}^{\prime}$ & $\begin{array}{l}\text { The distance between the } \\
\text { center of the nut and screw } \\
\text { raceway after deformation }\end{array}$ \\
\hline$\alpha_{i}$ & $\begin{array}{l}\text { The contact angle of the } i \text { th } \\
\text { ball }\end{array}$ & $\delta_{i}$ & $\begin{array}{l}\text { The contact deformation of } \\
\text { the } i \text { th ball }\end{array}$ \\
\hline$Q_{A n}$ & $\begin{array}{l}\text { The contact load between the } \\
\text { ball and the nut raceway in } \\
\text { nut A }\end{array}$ & $Q_{A s}$ & $\begin{array}{l}\text { The contact load between the } \\
\text { ball and the screw raceway in } \\
\text { nut A }\end{array}$ \\
\hline$Q_{B n}$ & $\begin{array}{l}\text { The contact load between the } \\
\text { ball and the nut raceway in } \\
\text { nut B }\end{array}$ & $Q_{B s}$ & $\begin{array}{l}\text { The contact load between the } \\
\text { ball and the screw raceway in } \\
\text { nut B }\end{array}$ \\
\hline
\end{tabular}

\section{Funding}

This study was funded by the National Natural Science Foundation of China (Grant No. 51905274), and National Science and Technology Major Projects of China (Grant No. 2018ZX04039001) 


\section{References}

[1] Nurhadi Hendro, et al. Experimental approached optimisation of a linear motion performance with grey hazy set and Taguchi analysis methods (GHST) for ballscrew table type. The International Journal of Advanced Manufacturing Technology, 2009, 44.1-2: 149-160.

[2] Mei XueSong, et al. Study on the load distribution of ball screws with errors. Mechanism and machine theory, 2003, 38.11: 1257-1269.

[3] Zhen Ni, An Qi. Analysis of stress and fatigue life of ball screw with considering the dimension errors of balls. International Journal of Mechanical Sciences, 2018, 137: 68-76.

[4] Zhao JiaJia, et al. Investigation of load distribution and deformations for ball screws with the effects of turning torque and geometric errors. Mechanism and Machine Theory, 2019, 141: 95-116.

[5] Du Zhe, et al. Study of the dynamic characteristics of ball screw with a load disturbance. Mathematical Problems in Engineering, 2016,

[6] Feng GuoHua, Pan YiLu. Investigation of ball screw preload variation based on dynamic modeling of a preload adjustable feed-drive system and spectrum analysis of ball-nuts sensed vibration signals. International Journal of Machine Tools and Manufacture, 2012, 52.1: 85-96.

[7] Bertolaso, Romuald, et al. Experimental and numerical study of the load distribution in a ball-screw system. Journal of Mechanical Science and Technology, 2014, 28.4: 1411-1420.

[8] Zhou ChangGuang, et al. Correlation between preload and no-load drag torque of ball screws. International Journal of Machine Tools and Manufacture, 2016, 102: $35-40$.

[9] Xu NanNan, et al. Modeling analysis and experimental study for the friction of a ball screw. Mechanism and Machine Theory, 2015, 87: 57-69.

[10]Tsai, P, C, et al. Ball screw preload loss detection using ball pass frequency. Mechanical Systems and Signal Processing, 2014, 48.1-2: 77-91.

[11]N. N. DIN ISO 3408-1 Vocabulary and designation, 2006.

[12]N. N. DIN ISO 3408-5 Acceptance conditions and acceptance tests, 2006. 
Figures

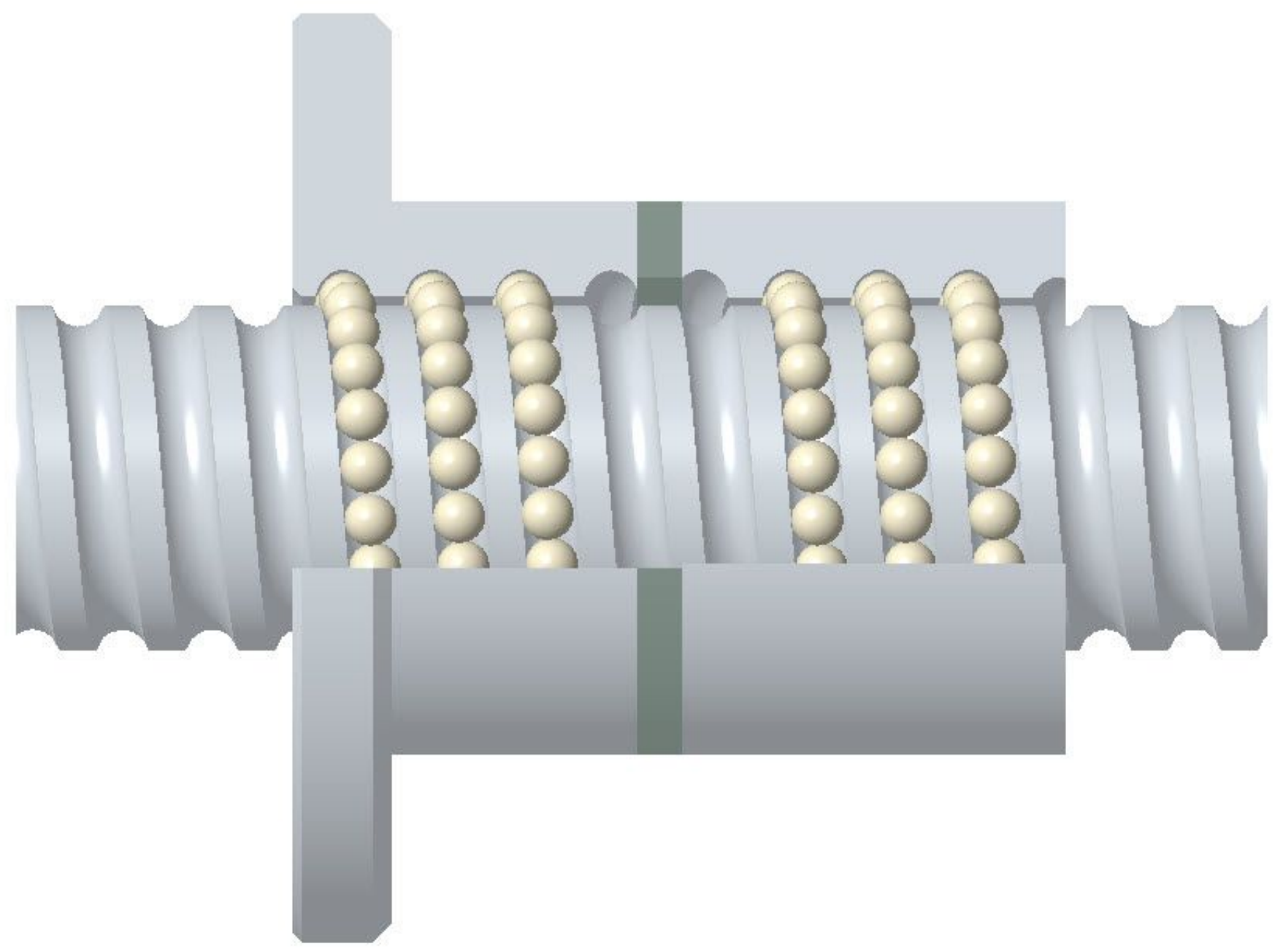

Figure 1

The structure of a double-nut ball screw 


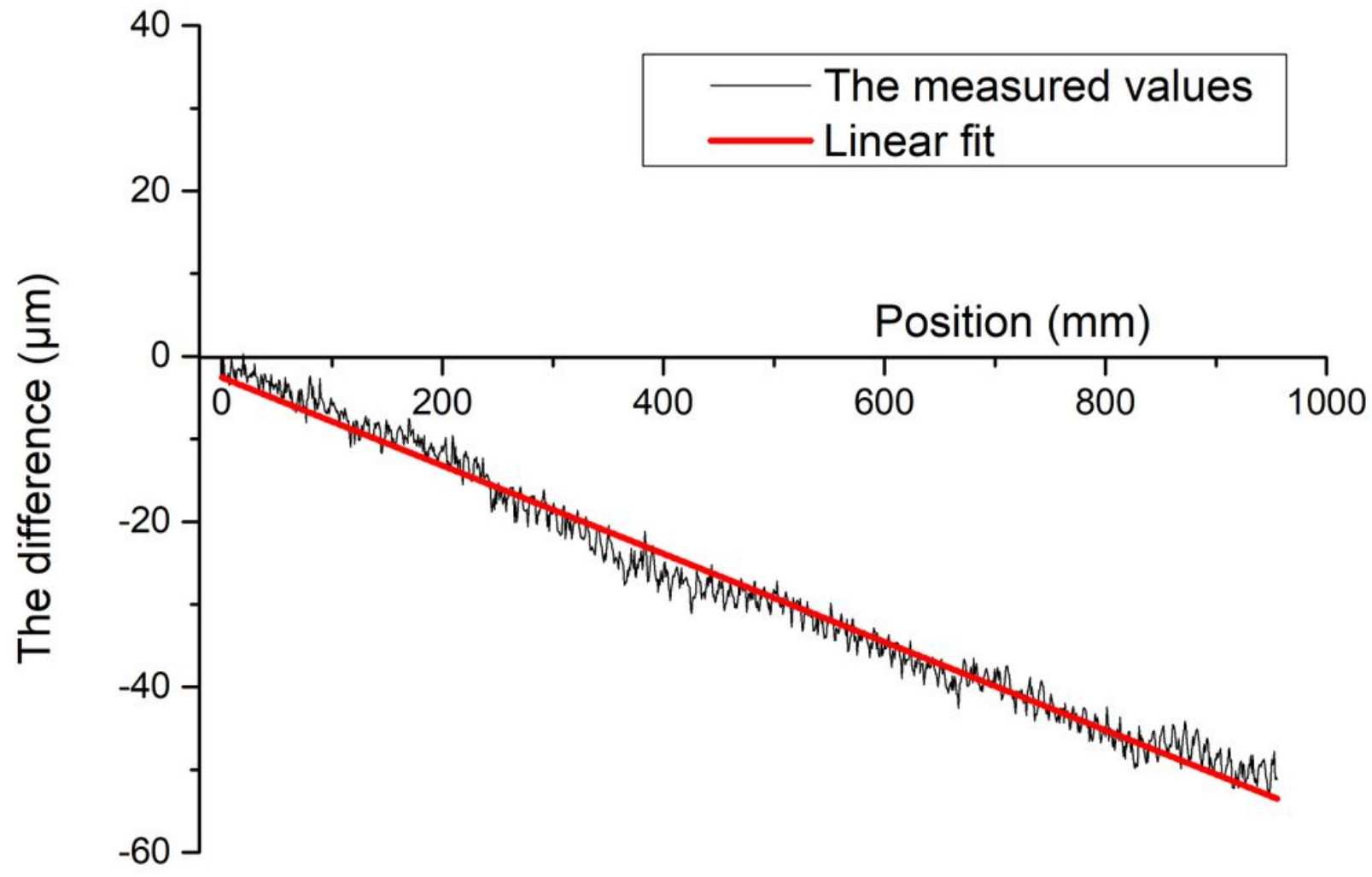

Figure 2

The difference between the actual travel and specified travel of a double-nut ball screw 


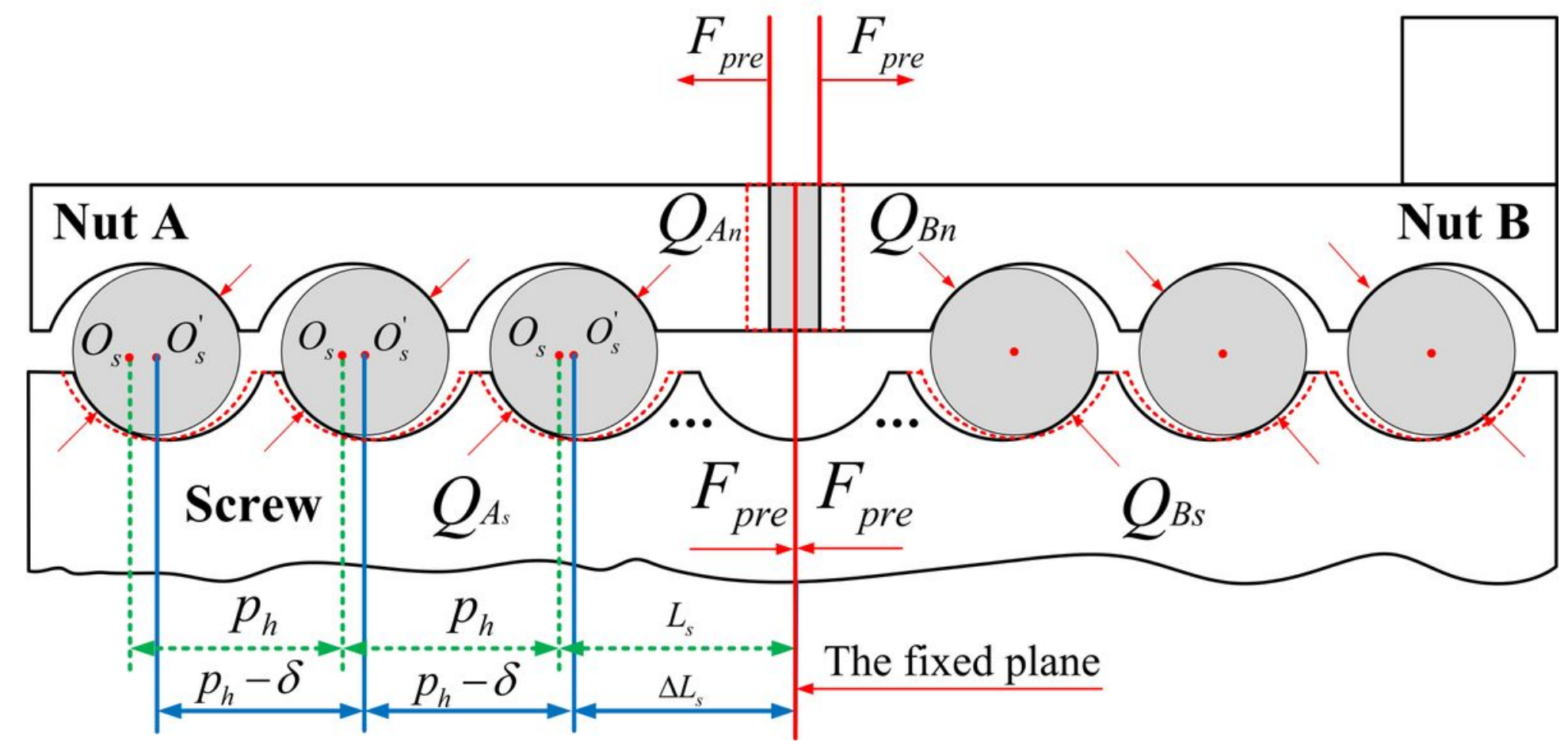

Figure 3

The displacement analysis of the screw under a preload 


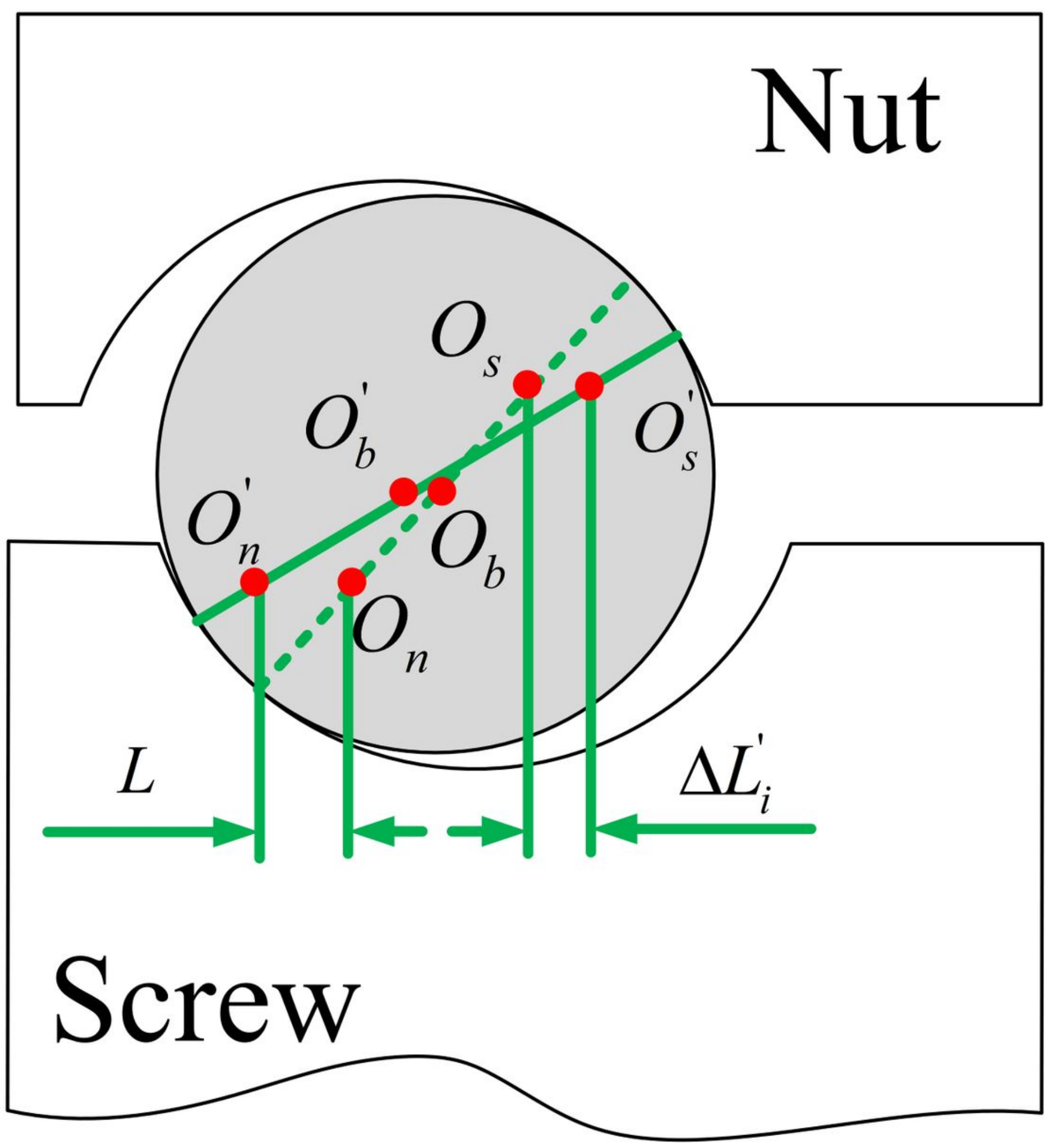

Figure 4

The deformation and displacement of the ith ball 

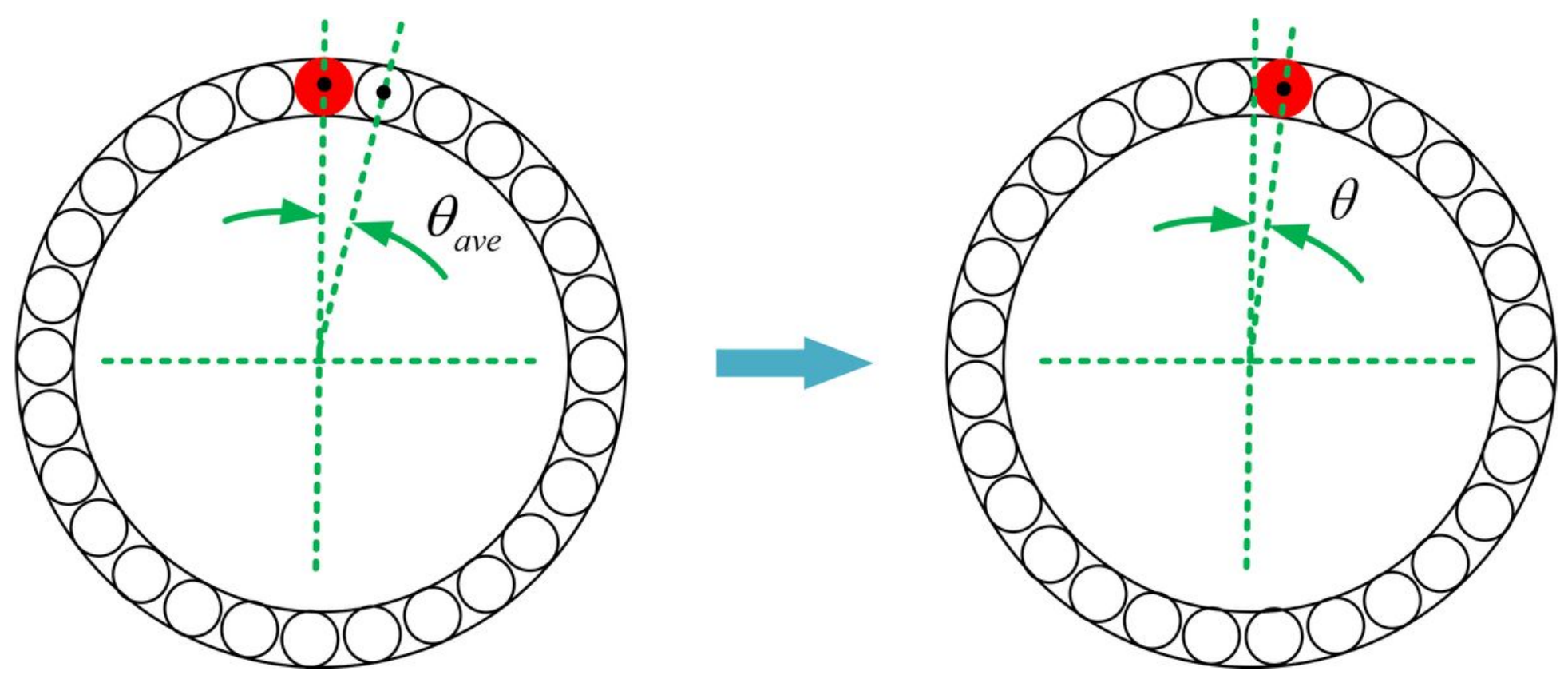

Figure 5

the movement of the balls in the raceway 


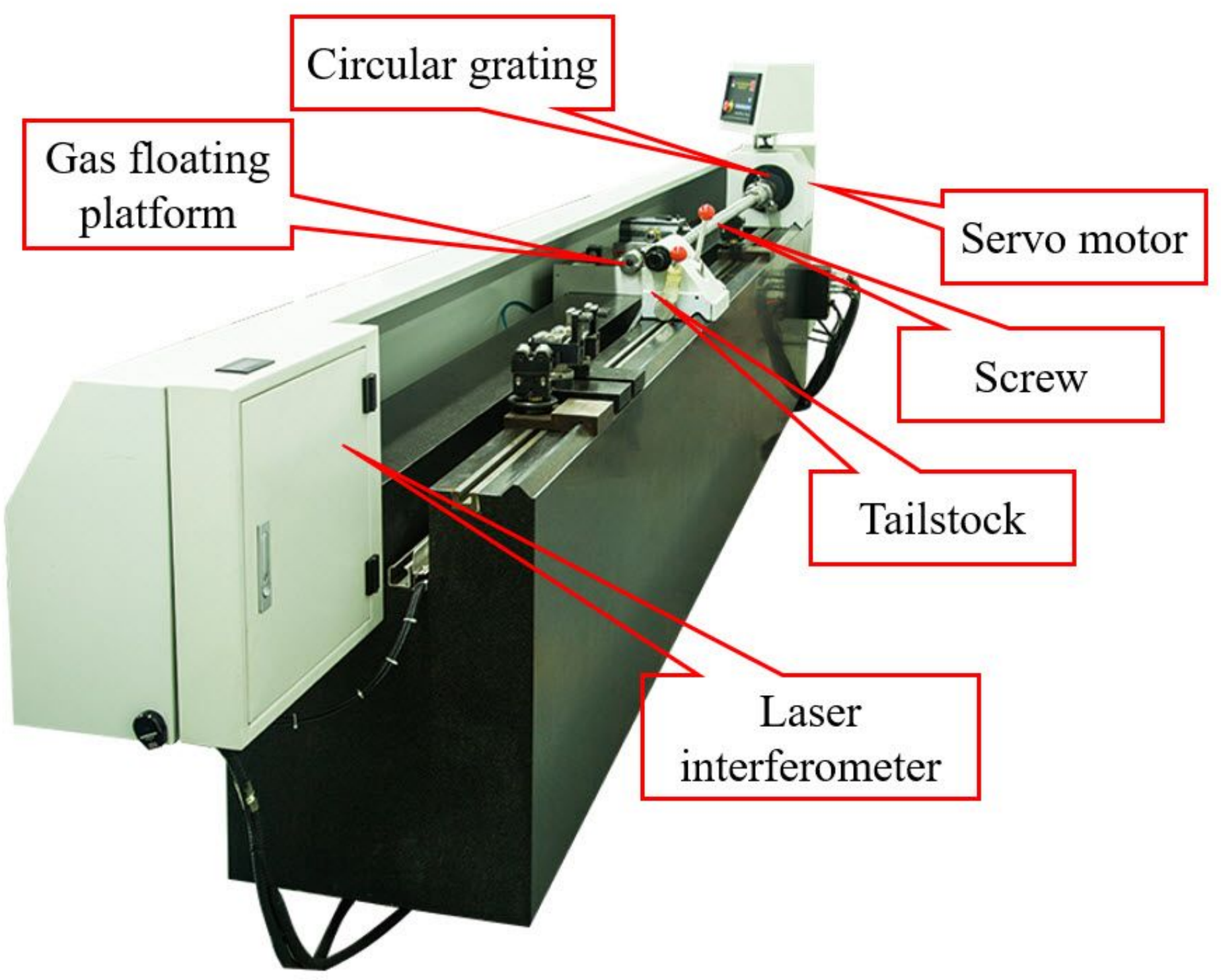

Figure 6

The structure of the ball screw lead errors measuring instrument 


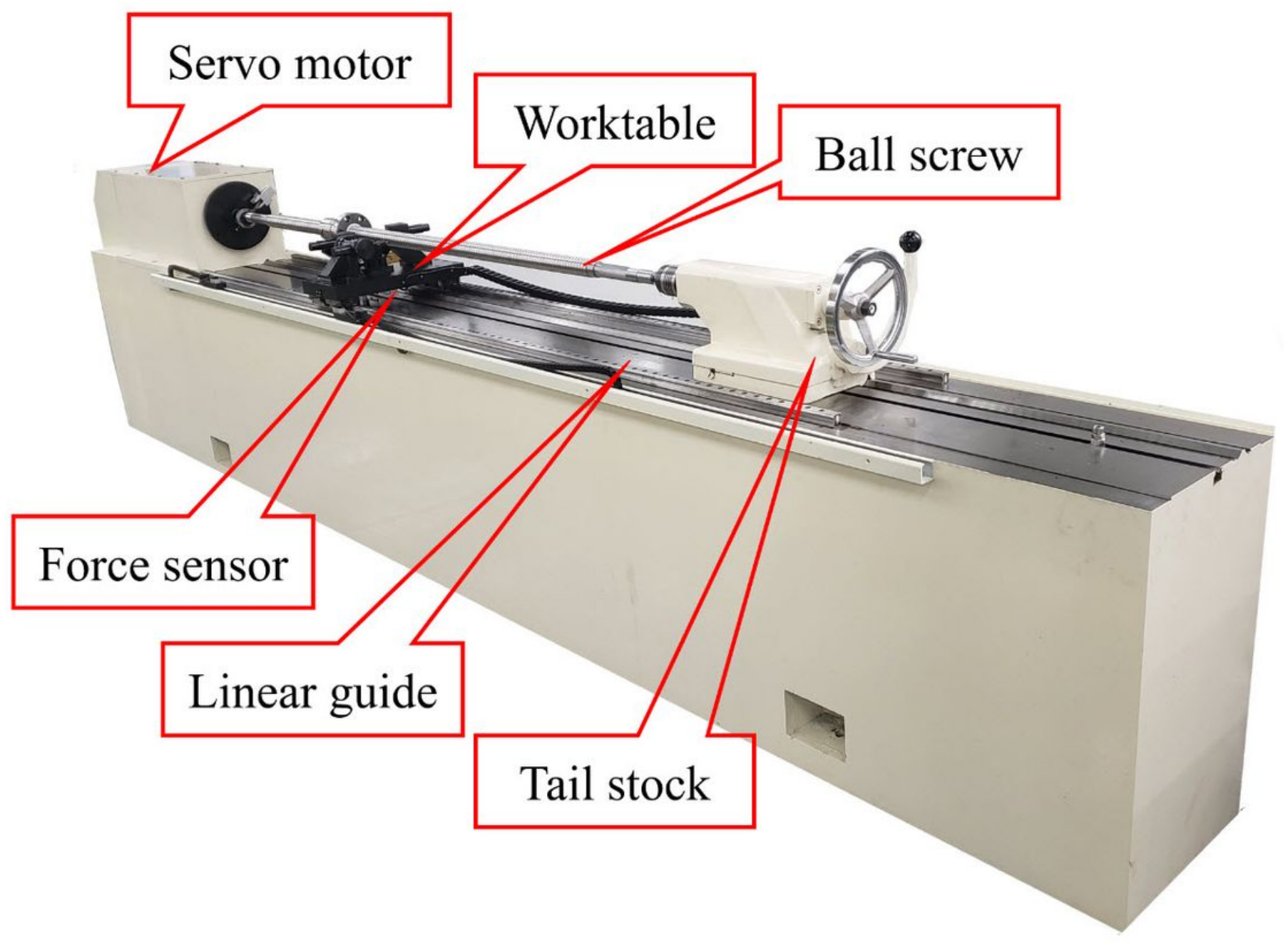

Figure 7

The structure of the ball screw no-load drag torque measuring instrument 


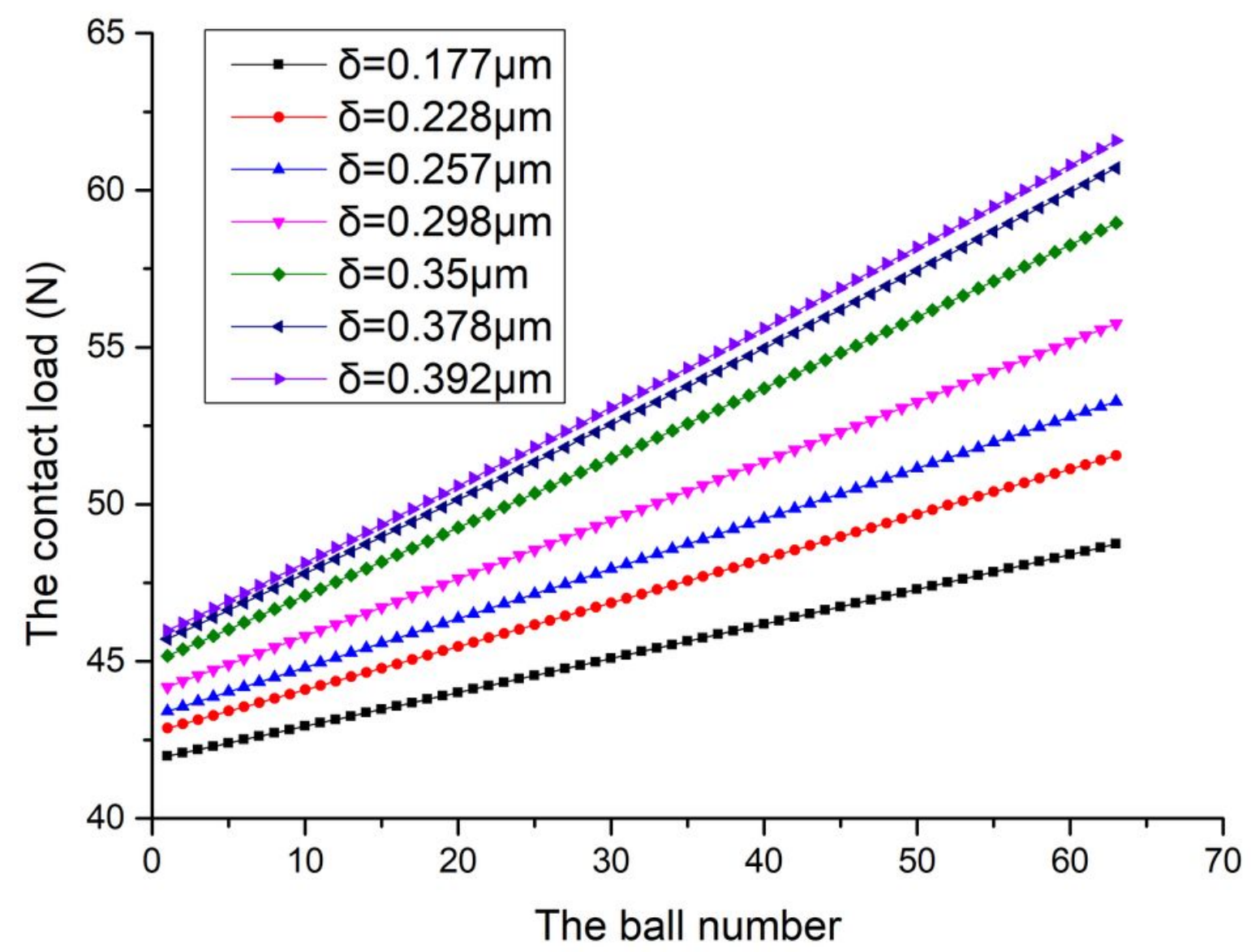

Figure 8

The contact load of the balls under different lead errors 


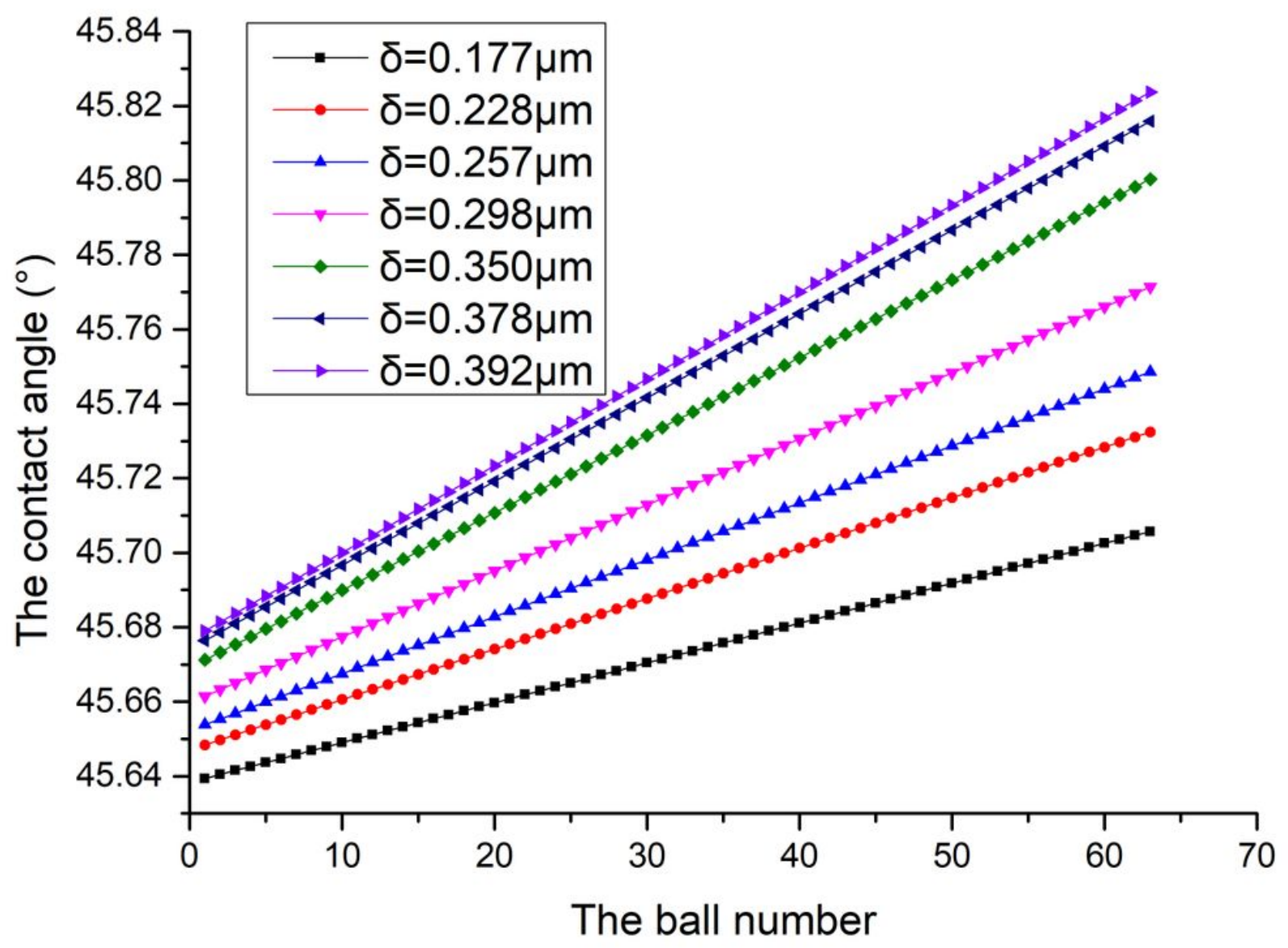

Figure 9

The contact angle of the balls under different lead errors 


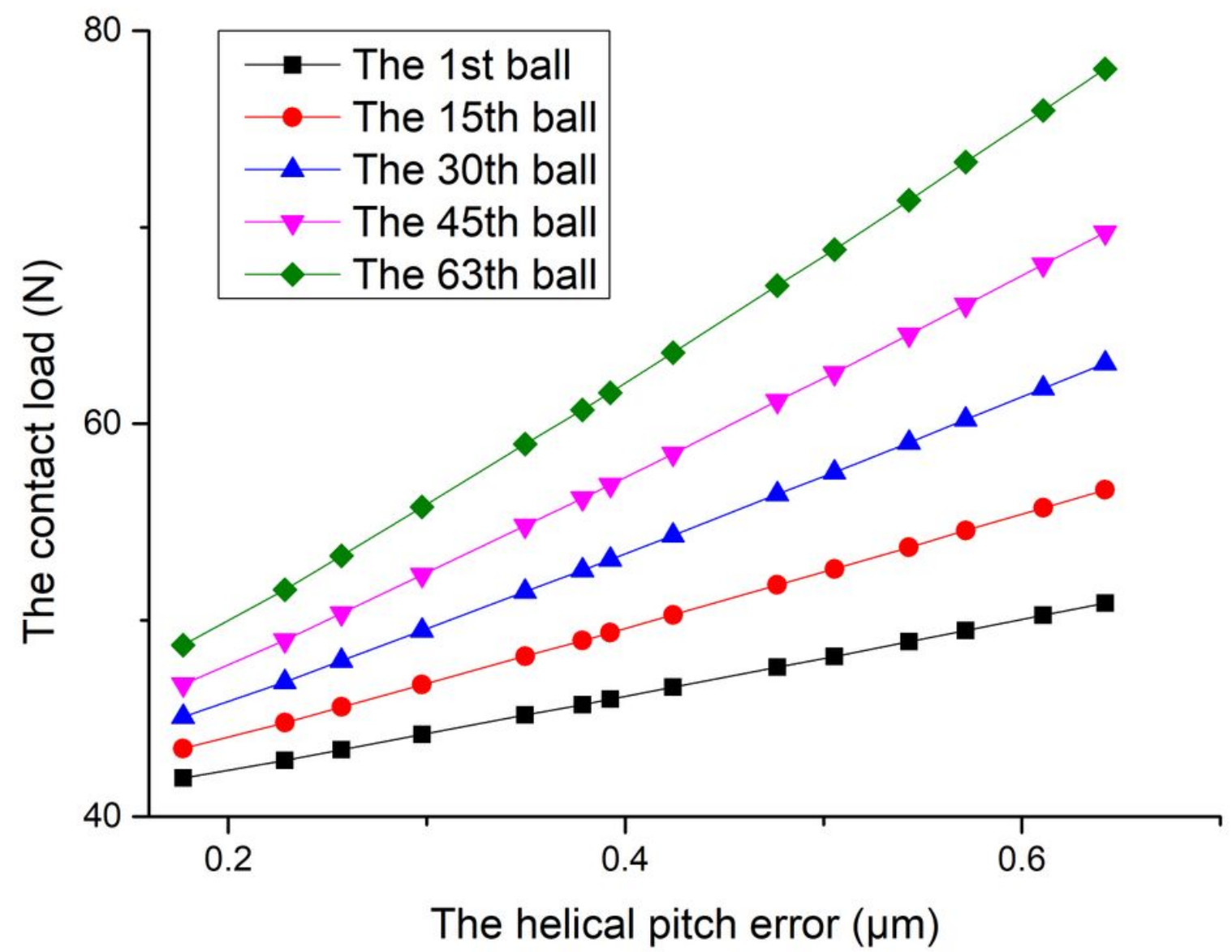

Figure 10

The relationship between the ball's contact load and the lead error 


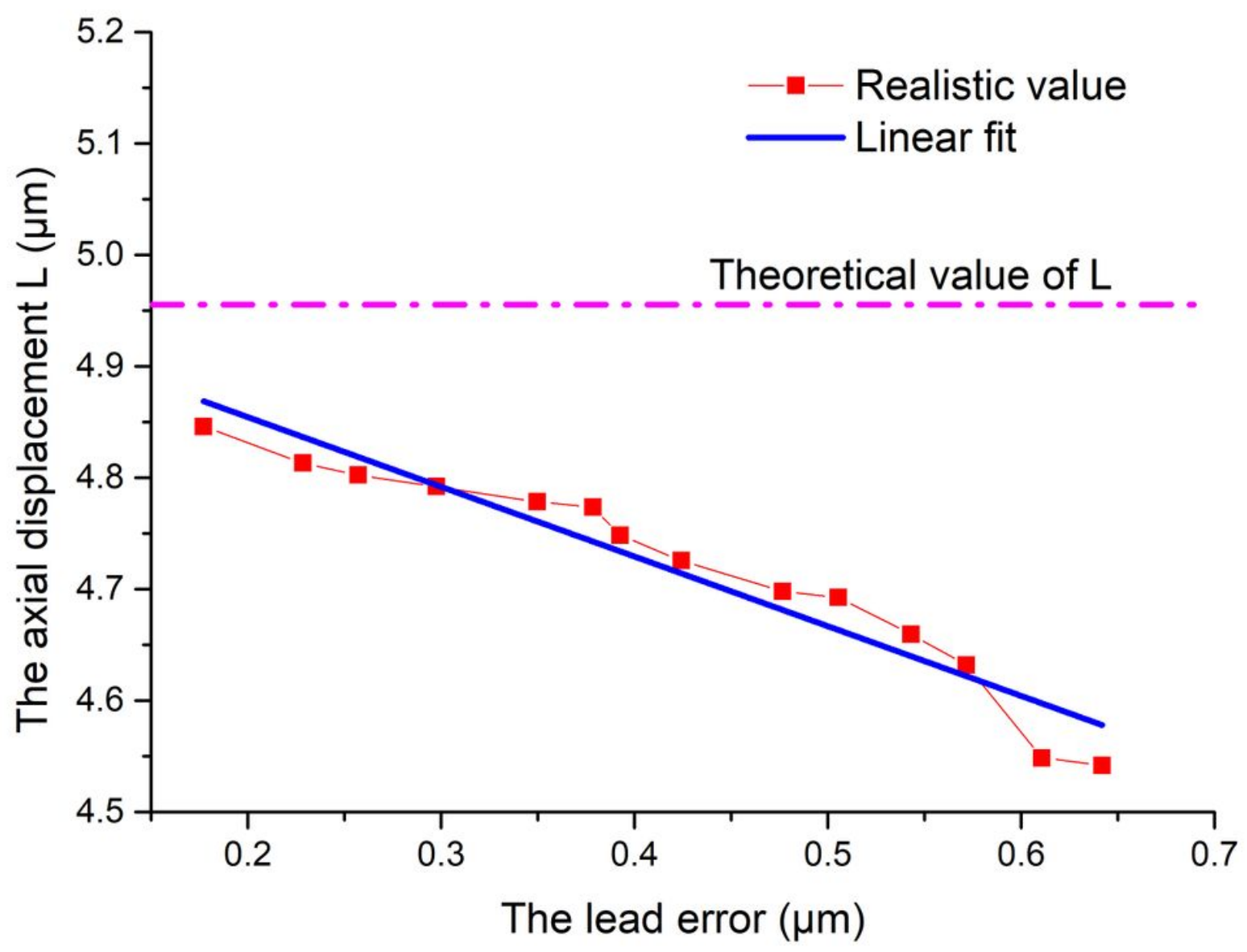

Figure 11

The calculated $L$ under different lead errors 


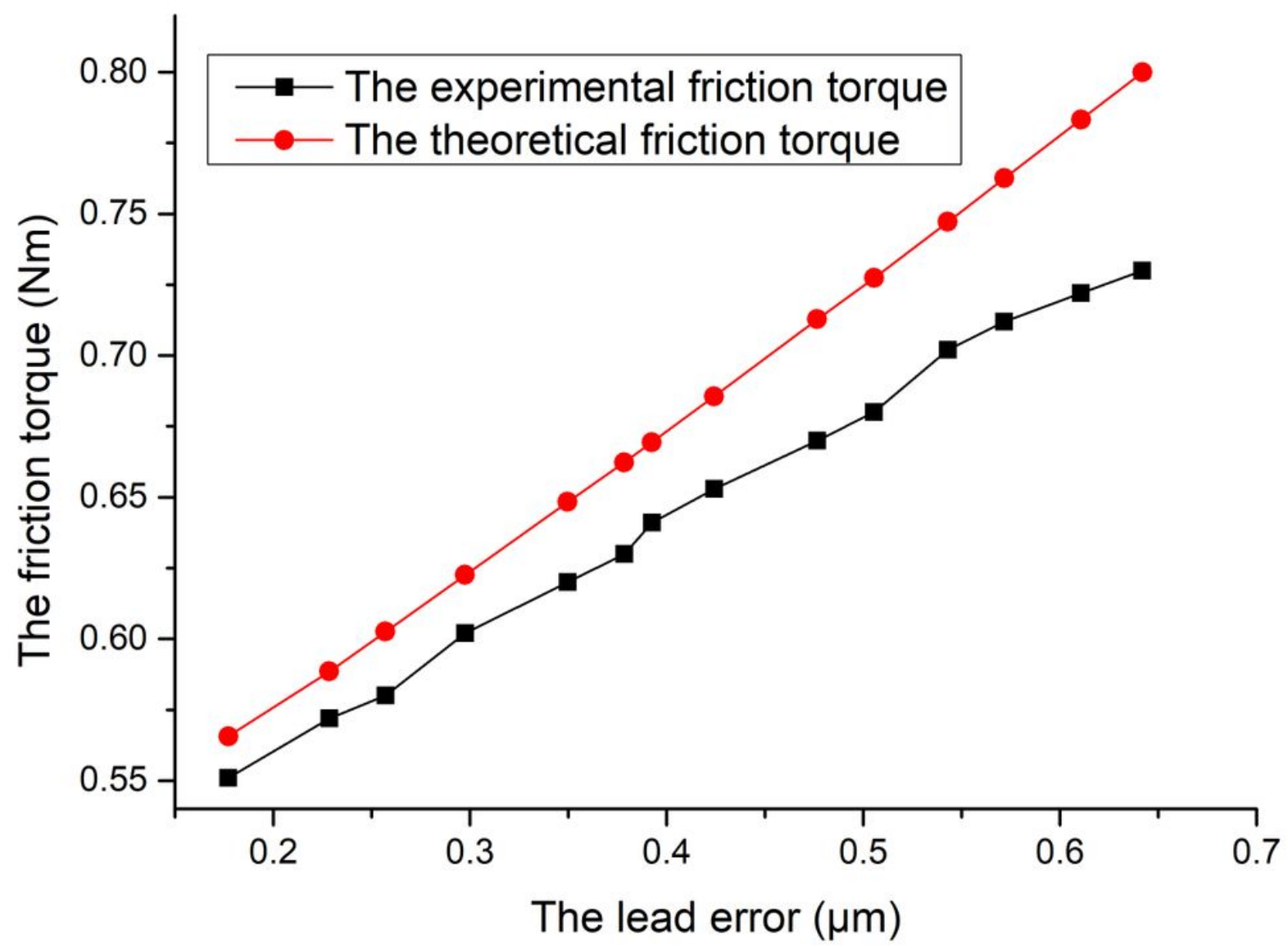

Figure 12

The relationship between the friction torque and the lead error 


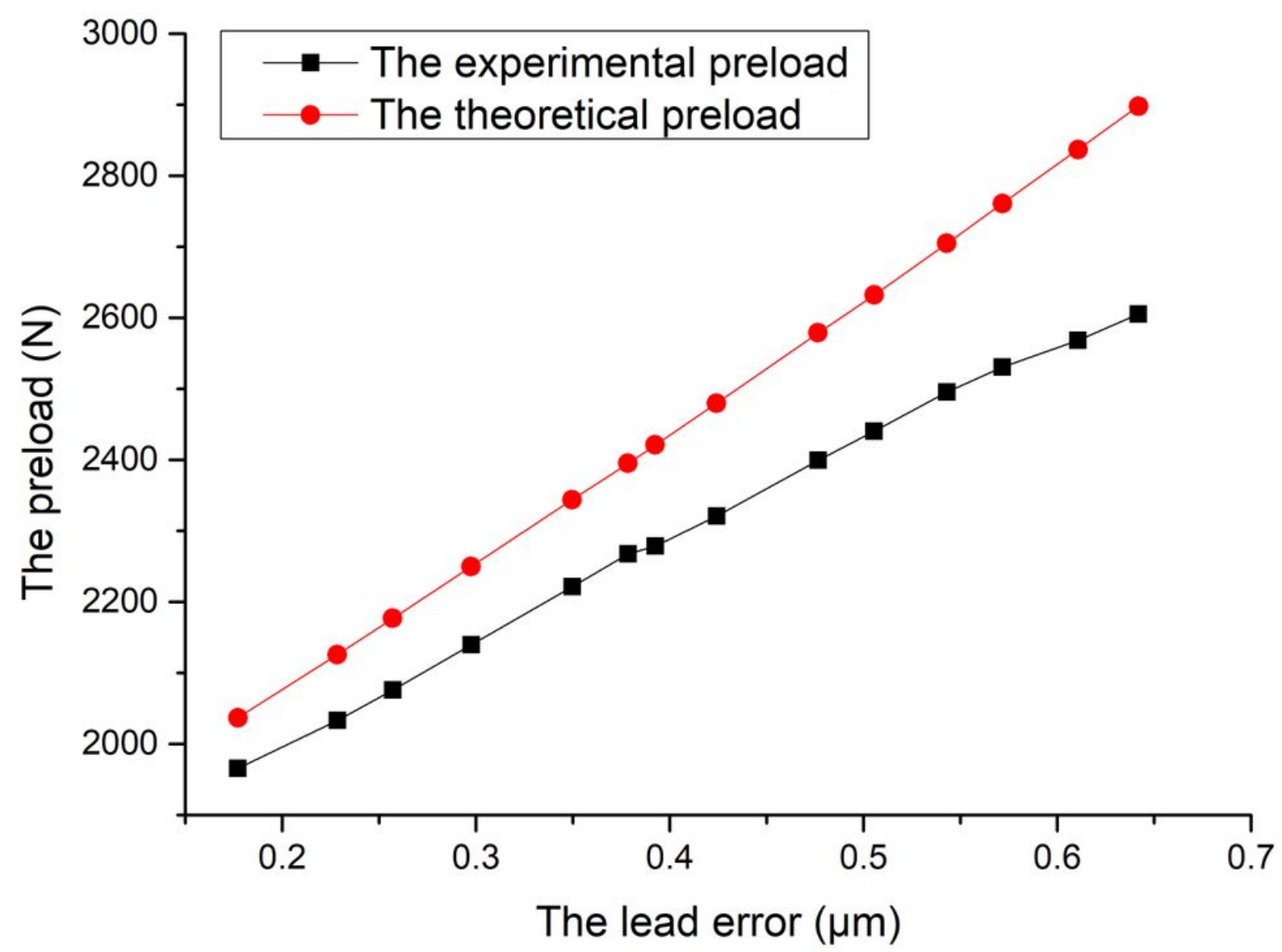

Figure 13

The relationship between the preload and the lead error 


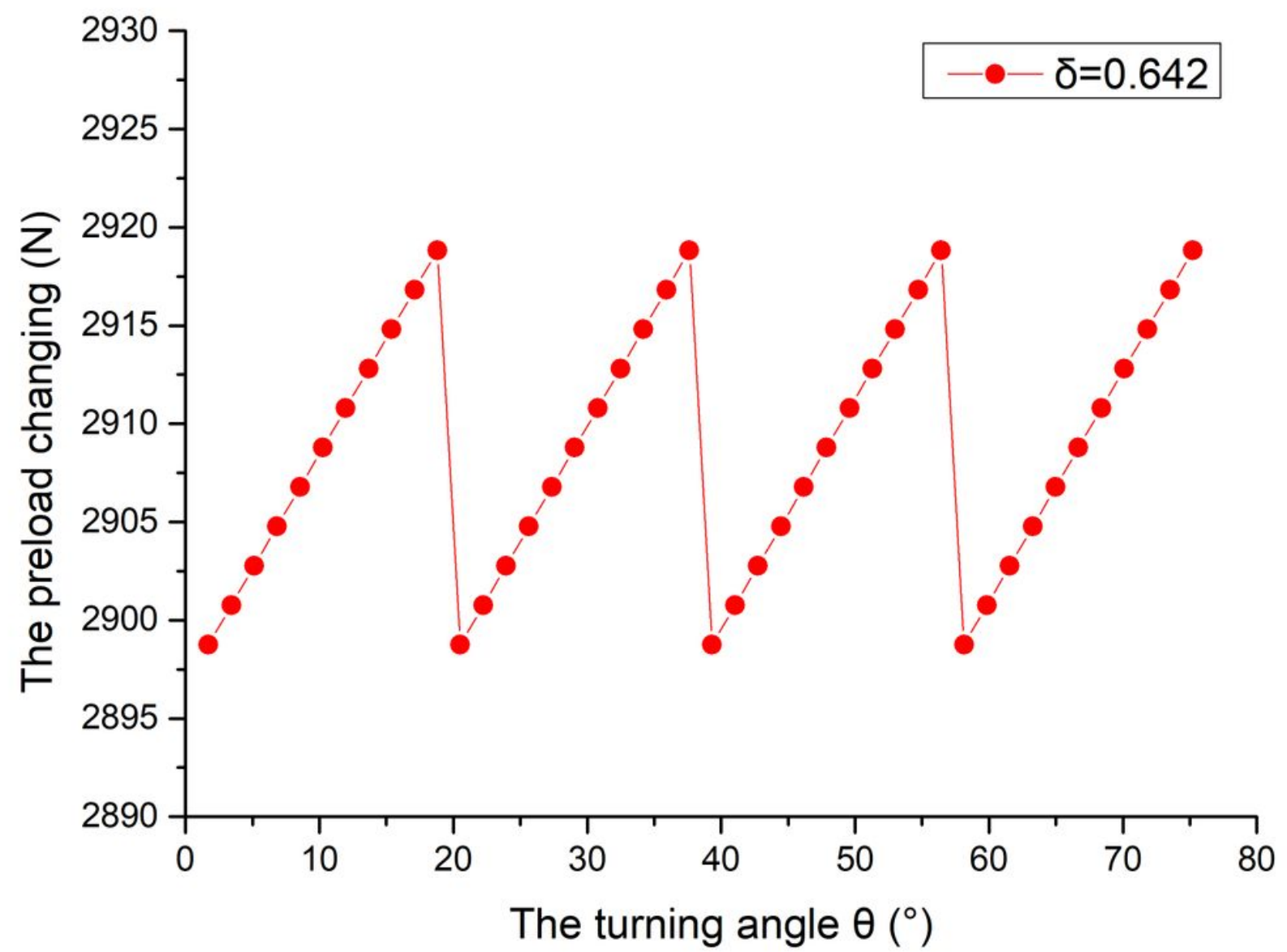

Figure 14

The correlation between the preload and the turning angle $\theta$ 


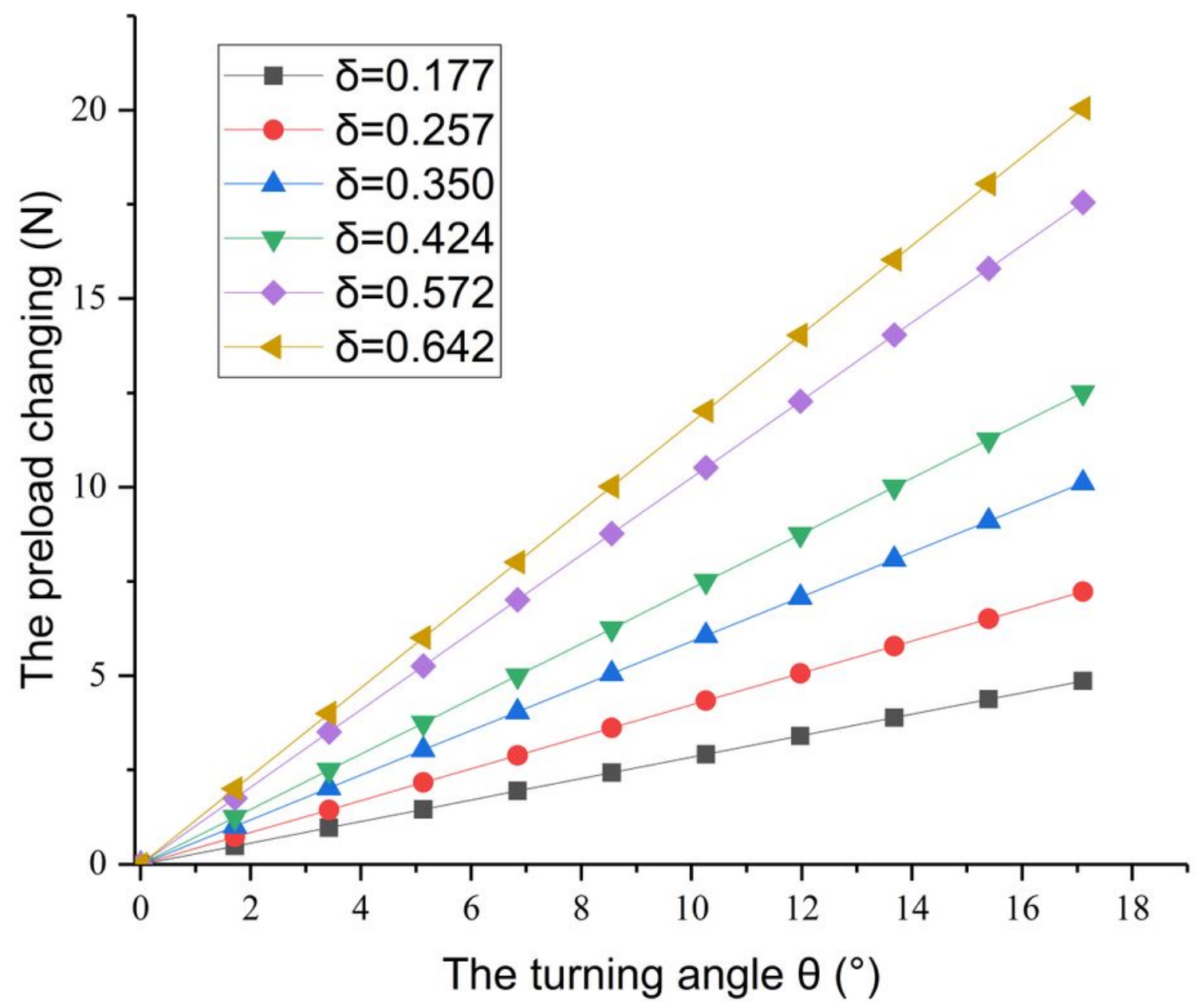

Figure 15

The relationship between the preload and the turning angle 


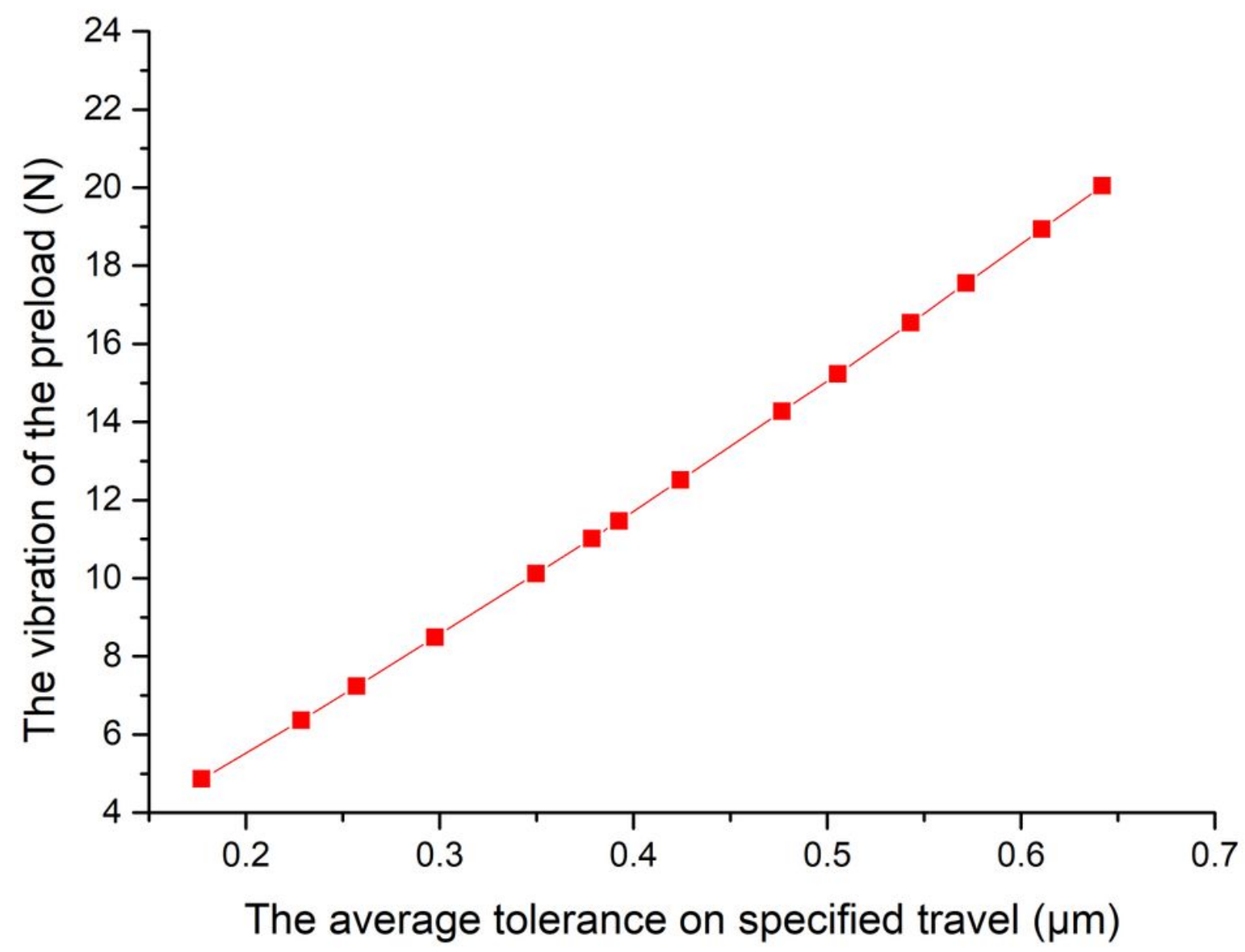

Figure 16

The vibration of the preload under different lead errors 